Check for updates

Cite this: Phys. Chem. Chem. Phys., 2019, 21, 20613

Received 2nd July 2019, Accepted 22nd August 2019

DOI: $10.1039 / c 9 c p 03731 d$

rsc.li/pccp

\section{Visualizing reaction and diffusion in xanthan gum aerosol particles exposed to ozone $\dagger$}

\author{
Peter A. Alpert, (D) *a Pablo Corral Arroyo, (D) ab Jing Dou, (D) ${ }^{c}$ Ulrich K. Krieger, (D) \\ Sarah S. Steimer, (iD d Jan-David Förster, iD e Florian Ditas, iD e \\ Christopher Pöhlker, (ID e Stéphanie Rossignol, ${ }^{\mathrm{fg}}$ Monica Passananti, (ID fhi \\ Sebastien Perrier, (iD ${ }^{f}$ Christian George, (iD ${ }^{f}$ Manabu Shiraiwa, (iD ${ }^{j}$ \\ Thomas Berkemeier, (D) ${ }^{\text {ek }}$ Benjamin Watts (D)' and Markus Ammann (D) *a
}

\begin{abstract}
Atmospheric aerosol particles with a high viscosity may become inhomogeneously mixed during chemical processing. Models have predicted gradients in condensed phase reactant concentration throughout particles as the result of diffusion and chemical reaction limitations, termed chemical gradients. However, these have never been directly observed for atmospherically relevant particle diameters. We investigated the reaction between ozone and aerosol particles composed of xanthan gum and $\mathrm{FeCl}_{2}$ and observed the in situ chemical reaction that oxidized $\mathrm{Fe}^{2+}$ to $\mathrm{Fe}^{3+}$ using $\mathrm{X}$-ray spectromicroscopy. Iron oxidation state of particles as small as $0.2 \mu \mathrm{m}$ in diameter were imaged over time with a spatial resolution of tens of nanometers. We found that the loss off $\mathrm{Fe}^{2+}$ accelerated with increasing ozone concentration and relative humidity, $\mathrm{RH}$. Concentric 2-D column integrated profiles of the $\mathrm{Fe}^{2+}$ fraction, $\alpha$, out of the total iron were derived and demonstrated that particle surfaces became oxidized while particle cores remained unreacted at $\mathrm{RH}=0-20 \%$. At higher $\mathrm{RH}$, chemical gradients evolved over time, extended deeper from the particle surface, and $\mathrm{Fe}^{2+}$ became more homogeneously distributed. We used the kinetic multi-layer model for aerosol surface and bulk chemistry (KM-SUB) to simulate ozone reaction constrained with our observations and inferred key parameters as a function of $\mathrm{RH}$ including Henry's Law constant for ozone, $\mathrm{H}_{\mathrm{O}_{3^{\prime}}}$ and diffusion coefficients for ozone and iron, $\mathrm{D}_{\mathrm{O}_{3}}$ and $D_{\mathrm{Fe}}$, respectively. We found that $\mathrm{H}_{\mathrm{O}_{3}}$ is higher in our xanthan gum/ $\mathrm{FeCl}_{2}$ particles than for water and increases when $\mathrm{RH}$ decreased from about $80 \%$ to dry conditions. This coincided with a decrease in both $D_{\mathrm{O}_{3}}$ and $D_{\mathrm{Fe}}$. In order to reproduce observed chemical gradients, our model predicted that ozone could not be present further than a few nanometers from a particle surface indicating near surface reactions were driving changes in iron oxidation state. However, the observed chemical gradients in $\alpha$ observed over hundreds of nanometers must have been the result of iron transport from the particle interior to the surface where ozone oxidation occurred. In the context of our results, we examine the applicability of the reacto-diffusive framework and discuss diffusion limitations for other reactive gas-aerosol systems of atmospheric importance.
\end{abstract}

\footnotetext{
${ }^{a}$ Laboratory of Environmental Chemistry, Paul Scherrer Institute, 5232 Villigen PSI, Switzerland. E-mail: Peter.Alpert@psi.ch, Markus.Ammann@psi.ch

${ }^{b}$ Institute for Physical Chemistry, ETH Zürich, 8092 Zürich, Switzerland

${ }^{c}$ Institute for Atmospheric and Climate Science, ETH Zürich, 8092 Zürich, Switzerland

${ }^{d}$ Department of Chemistry, University of Cambridge, Cambridge, CB2 $1 \mathrm{EW}, \mathrm{UK}$

${ }^{e}$ Multiphase Chemistry Department, Max Planck Institute for Chemistry, 55128 Mainz, Germany

${ }^{f}$ Univ. Lyon, Université Claude Bernard Lyon 1, CNRS, IRCELYON, F-69626, Villeurbanne, France

${ }^{g}$ Aix Marseille Université, CNRS, LCE UMR 7376, 13331 Marseille, France

${ }^{h}$ Institute for Atmospheric and Earth System Research/Physics, Faculty of Science, University of Helsinki, o0710, Helsinki, Finland

${ }^{i}$ Dipartimento di Chimica, Università di Torino, Via Giuria 5, 10125 Torino, Italy

${ }^{j}$ Department of Chemistry, University of California, Irvine, CA 92697-2025, USA

${ }^{k}$ School of Chemical \& Biomolecular Engineering, Georgia Institute of Technology, Atlanta, GA 30332, USA

${ }^{l}$ Laboratory for Synchrotron Radiation-Condensed Matter, Paul Scherrer Institute, 5232 Villigen PSI, Switzerland

$\dagger$ Electronic supplementary information (ESI) available. See DOI: 10.1039/c9cp03731d
} 


\section{Introduction}

Organic matter in atmospheric aerosol stems from a variety of natural and anthropogenic sources and is found in significant quantities in almost every single particle. ${ }^{1-3}$ Aerosol particles can both scatter and absorb light to varying degrees depending on their morphology and chemical composition, and they significantly impact the global radiative balance. ${ }^{4,5}$ These particles also act as nuclei for liquid droplets and ice in clouds. ${ }^{6-8}$ The fate of aerosol particles residing in the atmosphere is largely dependent on physical processes such as rain out and gravitational settling, but also on chemical transformation. ${ }^{9}$ Atmospheric aerosol particles are largely composed of organic and inorganic species such as sulfate, nitrate, ammonium, sea salts and trace metals, and this mix of compounds can influence uptake and internal production of oxidants. ${ }^{10}$ In turn, reactions in the condensed aerosol phase can lead to significant chemical change over time. ${ }^{11-13}$ For example, chemical reactions can lead to more oxygenated functionalities in particles thus increasing hydrophilicity leading to more efficient cloud condensation nuclei. ${ }^{14}$ On the other hand, less hygroscopic sea spray aerosol particles can result from first condensing organic acids, then chlorine displacement and finally the formation of sodium-organic salts that take up less water than marine halides. ${ }^{14,15}$ Aerosol particles dominated by organic matter can be highly viscous with physical properties similar to glass or tar, or they can exist in a more liquid-like state depending on location, altitude, temperature and relative humidity. ${ }^{16,17}$ Reactions in highly viscous particles can be diffusion limited, i.e. when the transport of the involved parent species is slow. This results in a reduced overall rate of reaction. ${ }^{17,18}$ There is a wealth of research into the effects of this phenomenon on chemical and physical aerosol processes and includes, in part, aerosol growth after nucleation, ${ }^{19-21}$ condensed phase reactions in secondary organic aerosol, ${ }^{22}$ water uptake and ice nucleation ${ }^{7}$ and preservation and transport of biomass burning tracer compounds ${ }^{23}$ or pollutants. ${ }^{13,24}$

Oxidants such as $\mathrm{OH}^{25-35}$ and $\mathrm{O}_{3}{ }^{36-41}$ reacting with micrometer and submicrometer sized organic aerosol particles in a humidified environment have been previously observed and modeled to increase our understanding of how these small molecules may diffuse through and react within atmospheric particles. Further studies have made great strides in developing model frameworks to describe experimental data, including modeling of chemical reactions at the surface and within the bulk of aerosol particles. ${ }^{29,32,35,36,42-52}$ In Shiraiwa et al., ${ }^{36}$ the chemical half life of amino acids in thin films of bovine serum albumin (BSA) at a relative humidity, $\mathrm{RH}$, of $90 \%$ and temperature, $T$, of $25{ }^{\circ} \mathrm{C}$ was determined to be about $5 \mathrm{~min}$ and increased to over an hour when $\mathrm{RH}<50 \%$. These authors used the kinetic multilayer model for aerosol surface and bulk chemistry (KM-SUB) to attribute this $\mathrm{RH}$ dependence on inhomogeneous mixing of reactants and products and calculated that at $\mathrm{RH}=50 \%$, the BSA diffusion coefficient was $10^{-20} \mathrm{~cm}^{2} \mathrm{~s}^{-1}$ with a viscosity close to that of a glass, ${ }^{36}$ typically greater than $10^{12} \mathrm{~Pa} \mathrm{~s}^{53-55}$ Ozone had a diffusion coefficient of $10^{-9} \mathrm{~cm}^{2} \mathrm{~s}^{-1}$ and was predicted only to be present and reacting in the first tens of nanometers of the BSA films. ${ }^{36}$ Heine et $a l .{ }^{41}$ found that the decay of squalene reacting with $\mathrm{O}_{3}$ over time was identical over the $\mathrm{RH}$ range of $0-60 \%$, leading them to use a stochastic multilayer model, Kinetiscope, to reproduce their results having a $1 \mathrm{~nm}$ adsorption layer where the reaction with $\mathrm{O}_{3}$ was predicted to mainly occur. This was supported by the authors' previous studies ${ }^{40}$ and their calculations of the $\mathrm{O}_{3}$ diffusion coefficient during reaction observed for particles with a 1-2 $\mathrm{nm}$ squalene coating. ${ }^{56}$ In an earlier study by Steimer et al., ${ }^{38}$ shikimic acid particles were chemically imaged with scanning transmission $\mathrm{X}$-ray microscopy coupled to near-edge X-ray absorption fine structure spectroscopy (STXM/NEXAFS) during $\mathrm{O}_{3}$ exposure as a function of $\mathrm{RH}$. The authors directly probed the $\mathrm{C}=\mathrm{C} 1 \mathrm{~s} \rightarrow \pi^{*}$ electronic transition and observed that reactive decay was highly dependent on RH, where shikimic acid lifetime increased 3 orders of magnitude when RH was decreased from 82 to $12 \%$. Later, Steimer et al. $^{39}$ measured $\mathrm{O}_{3}$ reactive uptake coefficients to shikimic acid in a comprehensive data set with high time resolution over seconds to $14 \mathrm{~h}$ at $\mathrm{RH}=92,83,68,45,24$ and $0 \%$, a constant $\mathrm{O}_{3}$ gas phase concentration, $\left[\mathrm{O}_{3}\right]_{\mathrm{g}}=178 \mathrm{ppb}$ and additionally for various $\left[\mathrm{O}_{3}\right]_{\mathrm{g}}=79,178,495$ and $1985 \mathrm{ppb}$ at $\mathrm{RH}=92$ and $24 \%$. This data set was a benchmark for a later modeling study by Berkemeier et al. ${ }^{49}$ using KM-SUB, who were able to determine physico-chemical parameters with high confidence such as chemical reaction kinetics of shikimic acid and reactive oxygen intermediates as well as changes in particle phase and molecular transport of $\mathrm{O}_{3}$, all of which would have otherwise been impossible under a narrow experimental range of $\mathrm{RH}$, time and $\left[\mathrm{O}_{3}\right]_{\mathrm{g}}$.

Observations and models mentioned above gave great insight to how molecules react and diffuse in aerosol particles, however there is a lack of direct observations of the internal chemical gradients throughout the bulk of a particle to compare against any model predictions until now. The term chemical gradient is defined here to describe a concentration gradient of a reactant inside an aerosol particle due to chemical reaction and diffusion. We use STXM/NEXAFS to image chemical gradients with $35 \mathrm{~nm}$ resolution inside organic aerosol particles in situ during $\mathrm{O}_{3}$ reaction at different $\mathrm{RH}$ and $\left[\mathrm{O}_{3}\right]_{\mathrm{g}}$. Steimer et al. ${ }^{38}$ were the first to attempt such a measurement. In a scenario where $\mathrm{O}_{3}$ loss is fast compared to its rate of transport, referred to as a reacto-diffusive limitation, $\mathrm{O}_{3}$ should not penetrate far into the particle interior. Instead, $\mathrm{O}_{3}$ would be limited to a characteristic length scale known as the reacto-diffusive length, which depends on its diffusion coefficient and first order loss rate. ${ }^{38}$ More precisely, it is the distance over which the $\mathrm{O}_{3}$ concentration in the condensed phase, $\left[\mathrm{O}_{3}\right]$, drops by a factor of $1 / e$. In Steimer et al. ${ }^{38}$ imaged chemical gradients in $\mathrm{C}=\mathrm{C}$ absorption signal were not discernible under dry conditions, while homogeneous degradation of $\mathrm{C}=\mathrm{C}$ occurred throughout the particles under humid conditions. Considering uncertainties due to image alignment, a low X-ray signal at thin particle edges and a limit on the contrast between $\mathrm{C}=\mathrm{C}$ absorption and total carbon, these authors hypothesized that shikimic acid loss was constrained to a too thin layer to become visible. ${ }^{38}$ Berkemeier et $a .^{49}$ later calculated the extent of the chemical gradient 
under low RH conditions to be well below $100 \mathrm{~nm}$ and beyond the resolution of STXM/NEXAFS.

In this study, we exposed particles composed of a mixture of xanthan gum (XG) and $\mathrm{FeCl}_{2}$ to $\mathrm{O}_{3}$ and observed internal chemical reaction gradients over time, $t$. Iron in $\mathrm{FeCl}_{2}$ has an oxidation state of +2 and transitions to an oxidation state of +3 when reacted with $\mathrm{O}_{3}$, i.e. from $\mathrm{Fe}^{2+}$ to $\mathrm{Fe}^{3+} \cdot{ }^{57-61}$ The use of iron in particles is a major benefit when employing STXM/ NEXAFS due to the fact that X-ray absorption peaks are strong, narrow and thus can be observed with much higher contrast to detect $\mathrm{Fe}^{2+}$ and $\mathrm{Fe}^{3+}$ compared to the absorption from carbon functionalities such as $\mathrm{C}=\mathrm{C}$ used in previous measurements. ${ }^{38,40}$ Additionally, we built on previous work ${ }^{62}$ and developed novel experimental and analytical procedures to quickly and efficiently quantify $\mathrm{Fe}^{2+}$ and $\mathrm{Fe}^{3+}$ for thousands of individual particles with a well-constrained uncertainty. In general, Fe containing aerosol particles are important, e.g. for their role in generating reactive oxygen species and free radicals in lung fluid and potentially leading to detrimential human health effects. ${ }^{63-66}$ Iron deposition impacts ocean fertilization and stimulating the growth of phytoplankton. ${ }^{67}$ Iron oxidation state can affect iron solubility, and iron can bind with organic ligands in atmospheric or oceanic particles influencing bioavailability in aquatic ecosystems. ${ }^{68-75}$ Moffet et al. ${ }^{62}$ used STXM/NEXAFS to quantify the $\mathrm{Fe}^{2+}$ fraction, $\alpha$, out of the total iron in ambient particles and calculated an average mass weighted value of $\alpha=0.33 \pm$ 0.08 during a pollution transport event from China to Japan, of which $\sim 5 \%$ of particles contained detectable iron. As a polysaccharide and biopolymer, XG is a unique model compound of marine derived organic matter in atmospheric aerosol. ${ }^{76}$ The change in XG composition by a few percent in water is enough to result in large changes in solution viscosity, a property that is highly desired for additives used in the food industry. ${ }^{77,78}$ XG hygroscopicity is of particular interest because when $\mathrm{RH}$ decreases, XG water content decreases and its viscosity increases. $^{76,79}$ We note that $\mathrm{XG}$ is a reference compound for quantifying what is known as "transparent exopolymer particles" in oceans ${ }^{80-82}$ which have recently been found in ambient air at concentrations of $2 \mu \mathrm{g} \mathrm{m}{ }^{-3}$ over the North Atlantic. ${ }^{83}$ For these reasons, the $\mathrm{XG} / \mathrm{Fe}^{2+}$ system is an interesting proxy for understanding molecular diffusion and reaction limitations in atmospheric marine derived aerosol.

Here, we used iron as a tracer for STXM/NEXAFS to unambiguously identify chemical gradients in oxidation state as the direct result of reaction and molecular diffusion limitation. These data were used to experimentally derive 2-D projected $\alpha$ profiles within thousands of individual particles in situ yielding the first direct evidence of chemical gradients in viscous particles. We report on how gradients change when particles were dry $(\mathrm{RH}=0 \%)$ or humidified at $\mathrm{RH}=20,40,60$ and $80 \%$. KM-SUB was used to model molecular transport and reaction in spherical shells of aerosol particles and derived 3-D radial profiles of $\alpha$ using known chemical reaction rates. These 3-D $\alpha$ profiles were then used to calculate 2 -D column integrated profiles of $\alpha$ for direct comparison with STXM/NEXAFS observations. Model parameters were diffusion coefficients for Fe and
$\mathrm{O}_{3}, D_{\mathrm{Fe}}$ and $D_{\mathrm{O}_{3}}$, and were described with a Vignes-type equation as a function of water mole fraction. Henry's Law constant for $\mathrm{O}_{3}$ in the XG/FeCl 2 matrix, $H_{\mathrm{O}_{3}}$, was also derived. Our STXM/NEXAFS spatio-chemical data allows a novel constraint for modeling aerosol internal chemical profiles, i.e. simultaneous reproduction of bulk $\mathrm{Fe}^{2+}$ depletion and the spatio-temporal evolution of $\mathrm{O}_{3}$ and $\mathrm{Fe}^{2+}$ reaction. In the context of our results, we discuss the applicability of the reacto-diffusive limiting case and the importance of direct observational constraints on model predictions of atmospheric aerosol chemical aging.

\section{Methods}

Mixed XG and $\mathrm{FeCl}_{2}$ particles were nebulized from dilute aqueous solution, dried and impacted onto silicon nitride membranes for exposure experiments and in situ STXM/NEXAFS analysis. Particle diameters on all samples were between 0.2 and $4.0 \mu \mathrm{m}$. Prior to impaction, silicon nitride substrates were preglued into removable sample exchange clips fitted to either of two microreactors named the PolLux environmental microreactor ${ }^{84}$ and the MPI-C aerosol micro-reactor. ${ }^{85}$ Both microreactors flow a stream of gas with controllable temperature, humidity and ozone content over particles remaining fixed on X-ray transparent membranes. Further details of the microreactors are provided in previous publications ${ }^{84,85}$ and specific operating conditions are provided in the ESI. $\dagger$ Particles were impacted onto the silicon nitride substrates and exposed to $\mathrm{He}, \mathrm{O}_{2}, \mathrm{H}_{2} \mathrm{O}$ and $\mathrm{O}_{3}$ at a desired partial pressure and $T_{\mathrm{p}}=20{ }^{\circ} \mathrm{C}$, and thus $\mathrm{RH}$ and reactive gas exposure could be well-controlled. ${ }^{38,84}$ Helium was used as a carrier gas with a flow of $20 \mathrm{~cm}^{3} \mathrm{~min}^{-1}$ at standard temperature and pressure. A flow of $\mathrm{O}_{2}$ at $5 \mathrm{~cm}^{3} \mathrm{~min}^{-1}$ first passed through a custom built UV lamp $\mathrm{O}_{3}$ generator then mixed with the humidified He flow. The concentration of $\mathrm{O}_{3}$ over $t$ was measured online using an absorption cell ${ }^{38}$ and is given in Fig. S1 of the ESI. $\dagger$ The calculated water partial pressure and $T_{\mathrm{p}}$ was used to determine the $\mathrm{RH}$ the particles were exposed to using the saturation vapor pressure parameterizations following Murphy and Koop. ${ }^{86}$ A total microreactor pressure of $150 \mathrm{mbar}$ and flow rate of $25 \mathrm{~cm}^{3} \mathrm{~min}^{-1}$ was maintained. The operating principle of the MPI-C aerosol micro-reactor is similar to the PolLux microreactor. The MPI environmental cell was coupled to the same gas flow system as the PolLux microreactor with equal gas flow rates. However, the cell pressure was maintained at $\sim 450 \mathrm{mbar}$. This allowed for a greater concentration of $\mathrm{O}_{2}$ in the $\mathrm{O}_{3}$ generator, and thus a greater $\left[\mathrm{O}_{3}\right]_{\mathrm{g}}$ for experiment with higher exposure. Detailed experimental methods are further outlined in the ESI. $\dagger$

The Fe oxidation state and carbon functionality was probed using STXM/NEXAFS at the PolLux endstation located at the Swiss Light Source (SLS). ${ }^{87}$ The transmission of X-ray photons through the particle was measured and converted to optical density, OD $=-\ln \left(I / I_{0}\right)$, where $I_{0}$ and $I$ are the incident and transmitted photon count, respectively, and their uncertainty is $\sigma_{I_{0}}=\sqrt{I_{0}}$ and $\sigma_{I}=\sqrt{I}$. X-ray light was focused to a 35 by $35 \mathrm{~nm}$ spot size while scanning a field of view (FOV) on the order of micrometers to generate an OD image at a single X-ray energy. 
An image was made of hundreds to thousands of individually measured pixels, where each is the OD over an area of $\simeq 10^{-3} \mu \mathrm{m}^{2}$. Multiple OD images over the same FOV taken over a range of X-ray energies were aligned and processed using publicly available software. $^{88}$ We primarily investigated the X-ray energy range between 700-735 eV, which is the Fe L-edge absorption. When present in particles, peak absorption due to $\mathrm{Fe}^{2+}$ and $\mathrm{Fe}^{3+}$ occur at slightly different X-ray energies, allowing to differentiate between the two. ${ }^{89,90}$ The X-ray energy at $\mathrm{Fe}^{2+}$ peak absorption for $\mathrm{FeCl}_{2}$ measured here was compared with previous literature ${ }^{62}$ and an energy offset was obtained as a calibration. Peak absorptions for ferrous and ferric chloride are at 707.8 and $709.5 \mathrm{eV}$, respectively ${ }^{62}$ as seen in Fig. 1. Using the parameterization from Moffet et al. ${ }^{62}$ $\alpha$ was determined from measuring the peak optical density, OD, corresponding to $\mathrm{Fe}^{2+}$ and $\mathrm{Fe}^{3+}$ indicated in Fig. 1 and taking their ratio, $r$. A more detailed description of our experimental methods, observations and how $r$ and $\alpha$ is calculated is given in the ESI. $\dagger$ In addition, a careful assessment of X-ray exposure used to not damage the particles while maximizing signal is also included (see Fig. S2 and S3, ESI $\dagger$ ).

The KM-SUB model was used to simulate chemical reaction and molecular transport inside of our $\mathrm{XG} / \mathrm{FeCl}_{2}$ particles and infer diffusion and solubility parameters. ${ }^{45,49}$ A detailed description of KM-SUB can be found in Shiraiwa et $a .^{45}$ and Berkemeier et al. $^{49}$ Briefly, this model solves the system of nonlinear differential equations for the time rate of change of $\mathrm{O}_{3}$ and $\mathrm{Fe}^{2+}$ in prescribed layers with defined thickness. It accounts for $\mathrm{O}_{3}$ accommodation and absorption, the $\mathrm{O}_{3}$ and $\mathrm{Fe}^{2+}$ diffusion from the surface and within bulk layers and finally, the chemical loss of $\mathrm{O}_{3}$ and $\mathrm{Fe}^{2+}$. The Knudsen number for our flow conditions was on the order of $10^{\circ}$ and $\gamma$ was on the order of $10^{-4}-10^{-6}$ during reaction. These were used to determine the gas diffusion

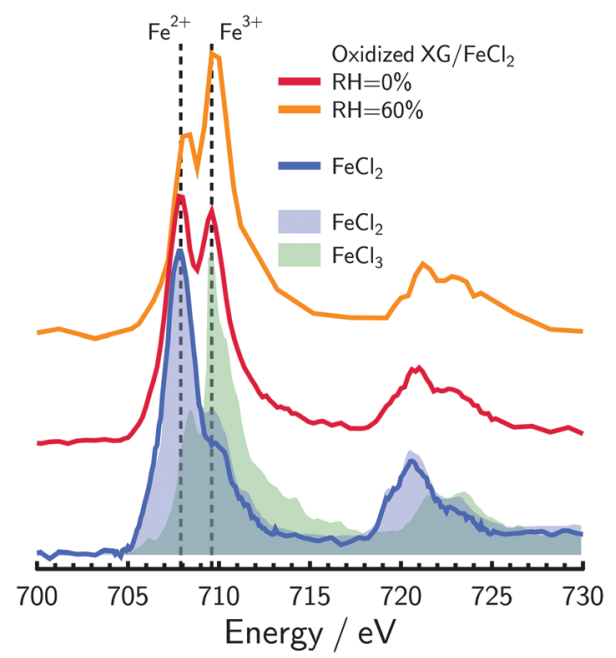

Fig. 1 Near edge $X$-ray absorption fine structure (NEXAFS) spectra of oxidized $\mathrm{XG} / \mathrm{FeCl}_{2}$ particles at $\mathrm{RH}=0$ and $60 \%$ shown as the red and orange lines, respectively, along with measured $\mathrm{FeCl}_{2}$ spectra as the blue line. Standards for ferrous and ferric chloride are shown as the blue and green shading, respectively. ${ }^{62}$ Spectra have been scaled and shifted vertically for clarity. Dashed lines indicate typical peak absorption for $\mathrm{Fe}^{2+}$ and $\mathrm{Fe}^{3+}$ at X-ray energies of 707.9 and $709.6 \mathrm{eV}$. correction factor $^{42}$ close to unity and thus was ignored. A single spherical aerosol particle geometry with $d_{\mathrm{p}}=0.5 \mu \mathrm{m}$ was applied for all simulations. The model had 2 spatial regions where the first extended from the surface to a short distance into the bulk and hosted 100 to 500 finely spaced layers to resolve the $\mathrm{O}_{3}$ concentration there. The surface typically had the strongest chemical gradients because $\mathrm{O}_{3}$ molecules that entered the particle were rapidly consumed by reaction with $\mathrm{Fe}^{2+}$. Care was taken to resolve $l_{\text {rd }}$ for both $\mathrm{O}_{3}$ and $\mathrm{Fe}^{2+}$ with multiple layers. The remaining particle bulk had evenly spaced layers with 0.5 to $2 \mathrm{~nm}$ thickness, which was sufficient to resolve observed $\mathrm{Fe}^{2+}$ gradients. The total number of layers in a simulation varied between 500-1500 depending on $\mathrm{O}_{3}$ and $\mathrm{Fe}^{2+}$ gradients. $\alpha_{0}$ was approximated to be uniform through the particle. The $\mathrm{O}_{3}$ uptake coefficient, $\gamma$, was calculated over time using the $\mathrm{O}_{3}$ surface coverage, the net flux from the gas phase to the surface and the collision flux ${ }^{45,49}$ shown in Fig. S9 in the ESI. $\dagger$ The model was modified to include a changing gas phase $\mathrm{O}_{3}$ concentration over $t$.

\section{Results and discussion}

\subsection{NEXAFS spectra}

Fig. 1 shows example NEXAFS spectra of oxidized XG/FeCl particles at dry and humidified conditions in comparison with the reference material $\mathrm{FeCl}_{2}$ measured here and $\mathrm{FeCl}_{2}$ and $\mathrm{FeCl}_{3}$ from literature. ${ }^{62}$ Two absorption peaks at 707.8 and $709.6 \mathrm{eV}$ were observed for oxidized $\mathrm{XG} / \mathrm{FeCl}_{2}$ particles and were in agreement with $\mathrm{Fe}^{2+}$ and $\mathrm{Fe}^{3+}$ peak absorption energies for $\mathrm{FeCl}_{2}$ and $\mathrm{FeCl}_{3}$, respectively. Although nearly identical peak positions were observed, we did not investigate how humidity and the organic polysaccharide matrix influences Fe electronic excitations in detail. Important to note from Fig. 1 is that only $\mathrm{Fe}^{2+}$ and $\mathrm{Fe}^{3+}$ peaks were observed in oxidized particles meaning that the total Fe concentration, $\left[\mathrm{Fe}_{\text {tot }}\right]=\left[\mathrm{Fe}^{2+}\right]+\left[\mathrm{Fe}^{3+}\right]$, where $\left[\mathrm{Fe}^{2+}\right]$ and $\left[\mathrm{Fe}^{3+}\right]$ is the concentration of $\mathrm{Fe}^{2+}$ and $\mathrm{Fe}^{3+}$ species, respectively, and

$$
\alpha=\left[\mathrm{Fe}^{2+}\right] /\left[\mathrm{Fe}_{\mathrm{tot}}\right]
$$

We note that X-ray absorption at the Fe L-edge was observed to be distributed homogeneously throughout the particles and never in dense localized regions (i.e. as immersed iron nanoparticles) indicating that iron was well-mixed in our experiments.

\subsection{Xanthan gum/ $\mathrm{FeCl}_{2}$ particles exposed to oxygen}

We performed exposure experiments of $\mathrm{XG} / \mathrm{FeCl}_{2}$ particles to $\mathrm{O}_{2}$ and observed no change in $\alpha$ as a function of $t$ at any RH we investigated (see Fig. S4 in the ESI $\dagger$ ). Therefore, any reaction taking place between $\mathrm{O}_{2}$ and $\mathrm{Fe}^{2+}$ over our time scales was considered negligible. Further discussion of reaction kinetics of $\mathrm{O}_{2}$ and $\mathrm{O}_{3}$ is discussed later in Section 4.5. The scatter in $\alpha$ for $\mathrm{O}_{2}$ exposure mostly fell within \pm 0.07 , which was the standard deviation of $\alpha$ for individual particles with a diameter, $d_{\mathrm{p}}$, seen in Fig. S5 in the ESI. $\dagger$ It is apparent that $\alpha$ values for larger particles have a smaller error. This is due to both the greater number of pixels and the greater signal statistics, i.e. 
larger particles are thicker, absorb more and thus, have a better signal to noise ratio. Particles with $d_{\mathrm{p}}<0.2 \mu \mathrm{m}$ (not shown) were discarded from our analysis because their error was typically larger than any physically realistic range in $\alpha$. The standard deviation of each data set indicated in Fig. S5 and plotted in Fig. S4 (ESI $\dagger$ ) was typically larger than the error propagated through quadrature. For the remainder of the manuscript, error bars on all $\alpha$ values are either \pm 0.07 or the propagated error, whichever is greater.

\subsection{Oxidation of xanthan gum/ $\mathrm{FeCl}_{2}$ particles by ozone}

Fig. 2 shows $\alpha$ averaged over all particles as a function of time, ozone exposure, $\phi$, and $\mathrm{RH}$. The most striking result is that under dry conditions where $\mathrm{RH}=0$ and $20 \%$, very little change in $\alpha$ was observed. At more humid conditions of $\mathrm{RH}=40,60$ and $80 \%$, average $\alpha$ values decreased noticeably over $t$. Although the green circles for $\mathrm{RH}=60 \%$ shows the greatest decrease in $\alpha$, this is a consequence of using higher $\left[\mathrm{O}_{3}\right]_{\mathrm{g}}$ (see Fig. S1 in the ESI $\dagger$ ). At $\mathrm{RH}=0,20$ and $60 \%$, shown as red, pink and green circles, respectively, $\left[\mathrm{O}_{3}\right]_{\mathrm{g}}$ was on the order of $10^{3} \mathrm{ppb}$ which was about 10 times higher than for $\mathrm{RH}=40$ and $80 \%$. Fig. 2b shows $\alpha$ as a function of $\phi=\int\left[\mathrm{O}_{3}\right]_{\mathrm{g}}(t) \cdot \mathrm{d} t$, where $\left[\mathrm{O}_{3}\right]_{\mathrm{g}}(t)$ is taken from Fig. S1 (ESI $\dagger$ ). Iron oxidation was greater at $\mathrm{RH}=80 \%$ than at any other $\mathrm{RH}$ as a function of $\phi$. This can be seen in particular at $\phi=10^{-3} \mathrm{~atm} \mathrm{~s}$, where the blue symbols reach $\alpha=0.3$ while all other data at $\mathrm{RH}<80 \%$ have higher $\alpha$. In general, as $\mathrm{RH}$ or $\left[\mathrm{O}_{3}\right]_{\mathrm{g}}$ increased, $\mathrm{O}_{3}$ heterogeneous reaction rates must have also increased.

We acquired chemical images with high spatial resolution to quantify $\alpha$ over the particles in two dimensions. To accomplish this, $\alpha$ was averaged over all pixels identified at the perimeter of particles irrespective of particle size. In other words, $\alpha$ was calculated from the particle perimeter to 1 pixel, or $35 \mathrm{~nm}$, from the surface. Then, all adjacent concentric pixels toward the particle center (from 1 to 2 pixels from the particle surface or 35-70 nm) were identified and their corresponding $\alpha$ values averaged. This continued toward the center of particles and generated a 2-D concentric profile of $\alpha$, which is also a column integrated profile.

Fig. 3 shows 2-D profiles of $\alpha$ as a function of time and the pixels (distance) from the perimeter of particles for all experiments.
More oxidation occurred at the perimeter than at the center of particles, and the chemical gradients were typically shallow for all RH. For example, $\alpha$ increased from 0.45 to 0.65 at $\mathrm{RH}=40 \%$ and $t=180 \mathrm{~min}$ (orange symbol color in Fig. 3c) over $\sim 0.5 \mu \mathrm{m}$. At $\mathrm{RH}=80 \%, \alpha$ increased from 0.25 to 0.35 for the same reaction time and distance. For $\mathrm{RH}=0$ and $20 \%, \alpha$ increased only from the surface to $\sim 0.2 \mu \mathrm{m}$ in depth, implying a stronger $\mathrm{Fe}^{2+}$ concentration gradient under dry conditions than for more humid conditions. Prior to exposure, initial values of $\alpha$ were not equivalent to 1 , implying that the short time spent in contact in ambient laboratory air was enough to trigger oxidation. However, we carefully quantified initial $\alpha$ prior to $\mathrm{O}_{3}$ exposure to ensure a high enough value for experiments as shown by the grey symbols in Fig. 3.

Observed 2-D profiles were likely to be influenced by 4 factors. The first is the plasticizing effect water has on viscous XG-containing particles to the extent that a greater water content likely enhanced $D_{\mathrm{O}_{3}}$. At low $\mathrm{RH}, D_{\mathrm{O}_{3}}$ may have been low enough to limit penetration to the particle bulk for further reaction with $\mathrm{Fe}^{2+}$ in line with our observations that $\alpha$ was always less at particle surfaces than at their center. The glass transition temperature of XG was previously determined to be -16.4 and $-23.3{ }^{\circ} \mathrm{C}$ for $\mathrm{RH}$ of 11 and $84 \%$, respectively. ${ }^{79}$ Although our experiments were performed at $20{ }^{\circ} \mathrm{C}$ which is significantly warmer than the glass transition temperature, we still expect sufficiently low diffusion coefficients as to limit reactions due to the fact that XG is thermally stable and its viscosity does not change much with temperature. ${ }^{78,91}$ Dawson et $a .^{76}$ extrapolated viscosity measurements in dilute XG aqueous solutions from Wyatt and Liberatore ${ }^{92}$ to higher concentrations and $\mathrm{RH}=80 \%$ obtaining $10^{13} \mathrm{~Pa} \mathrm{~s}$ at $20{ }^{\circ} \mathrm{C}$. We note that extrapolations beyond experimental conditions can be inaccurate. However, this high value is in line with our suggestion that XG remains highly viscous and possibly close to or in a glass-like state even at high humidity. As a consequence, slow molecular transport of $\mathrm{O}_{3}$ through the glassy XG matrix should contribute to our observed gradients.

The second effect on observed 2-D profiles and $\mathrm{RH}$-dependent oxidation kinetics is that $H_{\mathrm{O}_{3}}$ may increase under dry conditions in $\mathrm{XG}$ compared to water where the condensed phase ozone
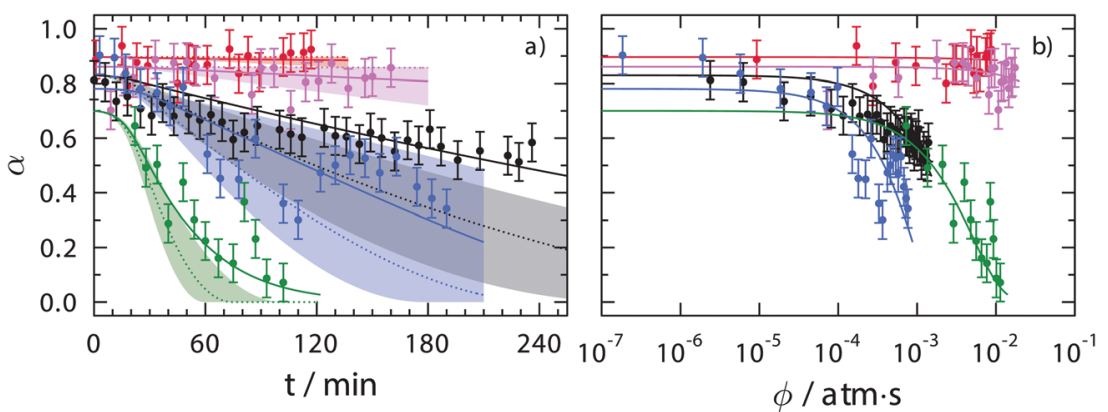

Fig. 2 Measured and modeled depletion of the Fe $\mathrm{Fe}^{2+}$ fraction, $\alpha$, as a function of (a) time, $t$, and (b) ozone exposure, $\phi$, for $\mathrm{RH}=0,22,43,60$ and $80 \%$ as red, pink, black, green and blue circles, respectively. Each data point was determined from approximately 5-25 particles each within a field of view imaged with STXM. The error bars are either \pm 0.07 or the propagated error from photon counting statistics, whichever is greater. Solid lines are calculations from the KM-SUB model using parameters given in Table 1. The dotted line and shadings in panel (a) are predictions applying the reactodiffusive framework described in more detail in the text. Shadings are not shown in panel (b) for clarity. 


\section{Distance From Perimeter / $\mathrm{nm}$}
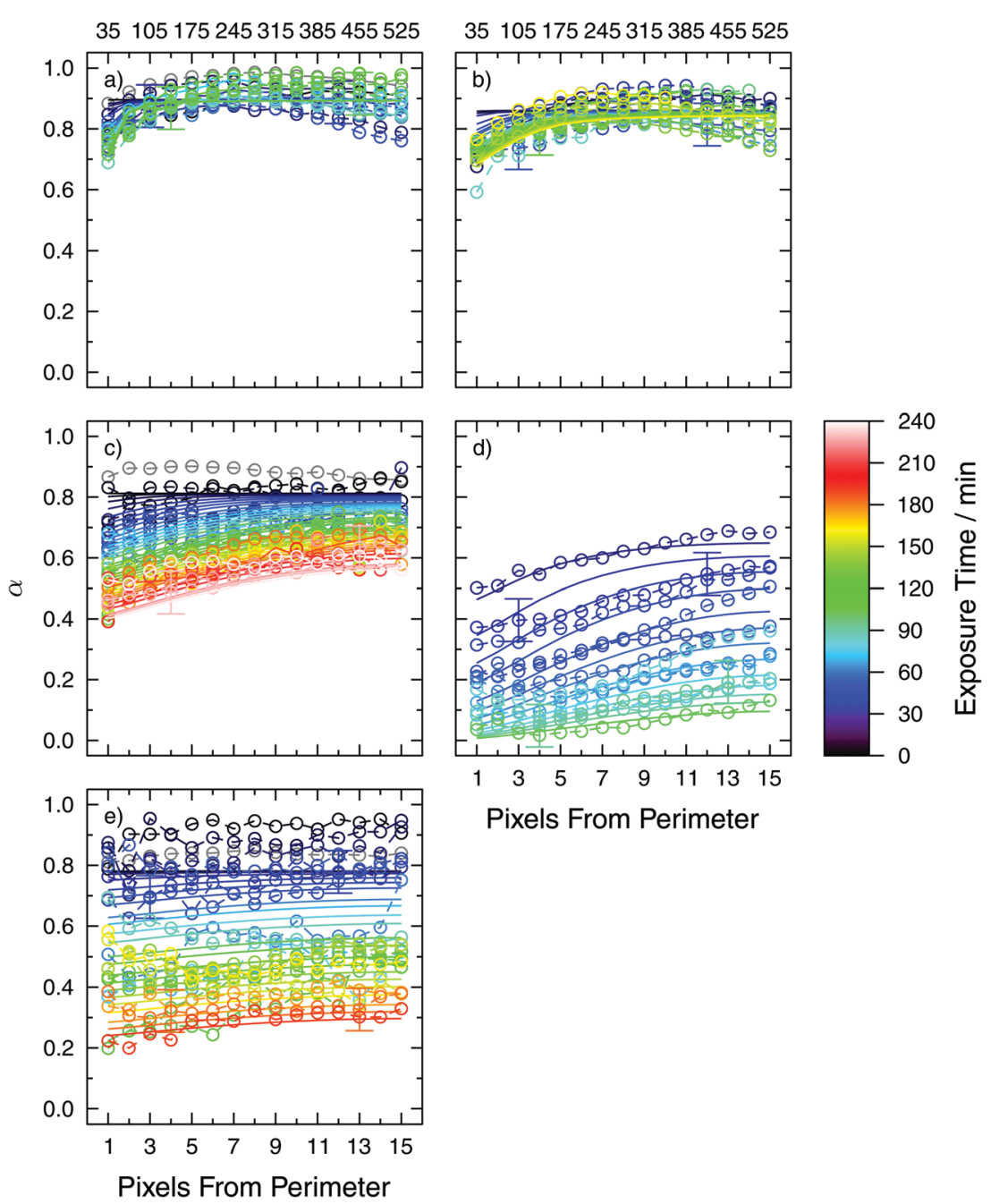

Pixels From Perimeter

Fig. 3 Observed and modeled 2-D profiles of the $\mathrm{Fe}^{2+}$ fraction, $\alpha$, as a function of $\mathrm{O}_{3}$ exposure time as the color scale at a $\mathrm{RH}$ of (a) $0 \%$, (b) $22 \%$, (c) $43 \%$, (d) $60 \%$ and (e) $80 \%$. Grey symbols are initial conditions prior to $\mathrm{O}^{3}$ exposure. Example error bars are included only on some data points for clarity. The bottom and top abscissa are the pixels and distance from the particle perimeter, respectively, where each pixel has a spatial dimension of 35 by $35 \mathrm{~nm}$. Solid lines are fit to this data with parameters given in Table 1.

concentration, $\left[\mathrm{O}_{3}\right]=H_{\mathrm{O}_{3}}\left[\mathrm{O}_{3}\right]_{g}$. It was observed previously that for pure shikimic acid, $\mathrm{H}_{\mathrm{O}_{3}}$ in organic material was about an order of magnitude higher than for $\mathrm{O}_{3}$ in water. ${ }^{38,49}$ Solubility of $\mathrm{O}_{3}$ is known to be higher in less polar solvents, thus it is expected that higher organic content (less polar than water) leads to an increase in $\mathrm{O}_{3}$ solubility. ${ }^{93}$ Higher values of $H_{\mathrm{O}_{3}}$ may increase condensed phase $\mathrm{O}_{3}$ concentration near the surface, increase the first order reaction rate there and cause stronger chemical gradients at low $\mathrm{RH}$. A third reason is the change in the diffusion coefficient of $\mathrm{Fe}$ as a function of RH. As XG is a hydrogel material that takes up water in subsaturated conditions, we hypothesize that the $\mathrm{Fe}$ diffusion coefficient, $D_{\mathrm{Fe}}$, should increase with increasing RH. A higher or lower value of $D_{\mathrm{Fe}}$ should result in more homogeneous or inhomogeneous $\alpha$ distribution, respectively, which is in line with our observations.

The fourth factor influencing 2-D profiles is dilution with water at higher RH. Water uptake will increase particle volume and cause $\left[\mathrm{Fe}_{\text {tot }}\right]$ to decrease and thus decrease the first order loss rate. Accounting for the water content as a function of RH between $0-80 \%$ given by Dawson et al. ${ }^{76}\left[\mathrm{Fe}_{\text {tot }}\right]$ varies by about $20 \%$. This is small and expected to have little effect compared to changing Henry's Law constant or the diffusion coefficient, which is typically orders of magnitude over a relatively narrow range in $\mathrm{RH}^{49,94}$ We argue that faster transport of $\mathrm{Fe}^{2+}$ out of the particle core and faster transport of $\mathrm{O}_{3}$ into the particle from the surface brings them together more readily allowing reactions to proceed at a faster rate at higher $\mathrm{RH}$.

\subsection{Prediction of molecular diffusion and solubility}

We have employed the KM-SUB model ${ }^{49}$ to infer values of $H_{\mathrm{O}_{3}}$, $D_{\mathrm{O}_{3}}$ and $D_{\mathrm{Fe}}$ shown in Fig. 4 which reproduce observed 2-D profiles in $\alpha$. Although KM-SUB has been previously constrained with data relating to the uptake of gas phase oxidants by particles, our data set is novel in that it is the first study to 


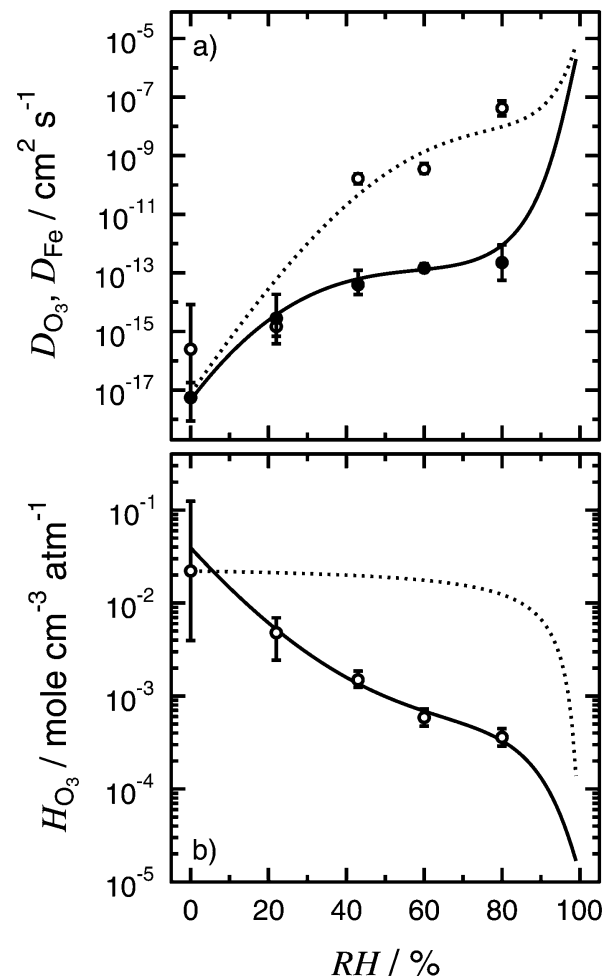

Fig. 4 Fitted parameters from the KM-SUB model. (a) The diffusion coefficient for $\mathrm{O}_{3}$ (white circles), $D_{\mathrm{O}_{3^{\prime}}}$ and the diffusion coefficient for $\mathrm{Fe}$ (solid symbols), $D_{\mathrm{Fe}}$, are shown as a function of $\mathrm{RH}$ for mixed xanthan gum and $\mathrm{FeCl}_{2}$ particles. A Vignes type parameterization for $D_{\mathrm{O}_{3}}$ and $D_{\mathrm{Fe}}$ are the dotted and solid lines, respectively. (b) Henry's Law constant for $\mathrm{O}_{3}, \mathrm{H}_{\mathrm{O}_{3^{\prime}}}$ as a function of $\mathrm{RH}$ is shown as white circles. Error bars indicate the fit sensitivity described in the text and the ESI. $\dagger$ The dotted and solid line is determined from a volume mixing rule and a Vignes type parameterization, respectively.

present spatially-resolved condensed-phase concentration profiles. We reiterate that KM-SUB has predicted aerosol particle internal radial composition profiles ${ }^{46,49,95}$ but up until now, there has been no direct observational evidence that they existed. For direct comparison with our observed profiles in Fig. 3, radial profiles from KM-SUB were converted to 2-D hemispherical projections of $\alpha$ described in more detail in the ESI $\dagger$ and shown in Fig. S6. We have fit modeled 2-D profiles to our observations for all $\mathrm{RH}$ each having 4 optimized parameters, $H_{\mathrm{O}_{3}}, D_{\mathrm{O}_{3}}$ and $D_{\mathrm{Fe}}$, as well as the initial $\mathrm{Fe}^{2+}$ fraction, $\alpha_{0}$. We note that the value of $\alpha_{0}$ was constrained by our observations, i.e. it was forced to be within our measurement and uncertainty range. All other parameters used in KM-SUB were taken from previous literature ${ }^{49}$ for shikimic acid and involve surface processes with $\mathrm{O}_{3}$. Although the authors did not use iron, we assume that the iron in combination with the xanthan gum matrix behaves as shikimic acid in Berkemeier et al. ${ }^{49}$ Parameter values and their descriptions can be found in Table 1 and described in the ESI. $\dagger$

A rate coefficient for $\mathrm{O}_{3}$ and $\mathrm{FeCl}_{2}$ was derived from previous studies $^{57-61}$ following,

$$
\mathrm{Fe}^{2+}+\mathrm{O}_{3} \rightarrow \mathrm{FeO}^{2+}+\mathrm{O}_{2}
$$

and

$$
\mathrm{FeO}^{2+}+\mathrm{Fe}^{2+}+2 \mathrm{H}^{+} \rightarrow 2 \mathrm{Fe}^{3+}+\mathrm{H}_{2} \mathrm{O} .
$$

The rate coefficient, $k$, for reaction (R1) has been reported ${ }^{57-61,96}$ in a range, $k=(1.7-8.2) \times 10^{5} \mathrm{M}^{-1} \mathrm{~s}^{-1}$ between a temperature of 20 and $25{ }^{\circ} \mathrm{C}$. Logager et al. ${ }^{59}$ claimed that for an excess of $\mathrm{Fe}^{2+}$, reaction (R2) should be the dominant sink for $\mathrm{FeO}^{2+}$ (ferryl iron) with $k=1.4 \times 10^{5} \mathrm{M}^{-1} \mathrm{~s}^{-1}$. Production of $\mathrm{OH}^{\bullet}$ and reaction with $\mathrm{FeO}^{2+}$ is also negligible with an excess of $\mathrm{Fe}^{2+} .{ }^{29}$ In general, $\mathrm{FeO}^{2+}$ is a very selective reactant and only oxidizes electron-rich organics, ${ }^{97}$ thus we suspect XG plays no role in oxidation of iron with $\mathrm{O}_{3}$. Aerosol particles used in our experiments had $\left[\mathrm{Fe}^{2+}\right]$ on the order of $1 \mathrm{M}$ implying that reaction (R2) is very fast. Therefore, we suggest the net reaction

$$
2 \mathrm{Fe}^{2+}+\mathrm{O}_{3} \stackrel{2 \mathrm{H}^{+}}{\longrightarrow} 2 \mathrm{Fe}^{3+}+\mathrm{O}_{2}+\mathrm{H}_{2} \mathrm{O},
$$

where $k_{\mathrm{R} 1}=k_{\mathrm{R} 3}$. We use $k_{\mathrm{R} 3}=3.7 \times 10^{5} \mathrm{M}^{-1} \mathrm{~s}^{-1}$ (which is the geometric mean of reported $k_{\mathrm{R} 1}$ values) equivalent to $6.2 \times$ $10^{-16} \mathrm{~cm}^{3} \mathrm{~s}^{-1}$ indicated in Table 1 to model bulk $\mathrm{O}_{3}$ reaction in our particles. It is important to note that the measured temperature dependence ${ }^{96}$ of $k_{\mathrm{R} 1}$ between 20 and $25^{\circ} \mathrm{C}$ is negligible compared to measurement variability given above.

Fig. 3 shows that the optimization of model-generated 2-D $\alpha$ profiles (solid lines) agree well with our measurements (circles), which is remarkable considering the large differences in $\left[\mathrm{O}_{3}\right]_{\mathrm{g}}$ and the long exposure time on the order of hours. Consistently, Fe was predicted to remain more reduced in particle cores than at particle surfaces. Although not explicitly fit, the modeled $\alpha$ averaged over the entire particle, shown as solid lines in Fig. 2, captures the observed decay and reveals the consistency between modeled and measured $\alpha$. The fitting parameters, $H_{\mathrm{O}_{3}}, D_{\mathrm{O}_{3}}$ and $D_{\mathrm{Fe}}$ are given in Table 1 and shown in Fig. 4 . We note that there is an obvious and expected trend that as RH decreases, both $D_{\mathrm{O}_{3}}$ and $D_{\mathrm{Fe}}$ values decrease and $H_{\mathrm{O}_{3}}$ increases. A model sensitivity analysis on $H_{\mathrm{O}_{3}}, D_{\mathrm{O}_{3}}$ and $D_{\mathrm{Fe}}$ is detailed in the ESI $\dagger$ (Fig. S10 and S11). Following previous work, ${ }^{49}$ we calculated the parameter range at which the sum of the squared residual values between observed and model derived 2-D profiles in $\alpha$ varied by $20 \%$, indicated as error bars in Fig. 4.

With regard to $\mathrm{O}_{3}$ transport, $D_{\mathrm{O}_{3}}$ at $\mathrm{RH}=0 \%$ was equal to $2.48 \times 10^{-16} \mathrm{~cm}^{2} \mathrm{~s}^{-1}$ and increased about 8 orders of magnitude to $4.17 \times 10^{-8} \mathrm{~cm}^{2} \mathrm{~s}^{-1}$ at $\mathrm{RH}=80 \%$. At this high humidity, $D_{\mathrm{O}_{3}}$ was 3 orders of magnitude less than for water, $D_{\mathrm{O}_{3}}^{\circ}=1.9 \times$ $10^{-5} \mathrm{~cm}^{2} \mathrm{~s}^{-1}$ taken from previous work. ${ }^{49,98}$ Following the Stokes-Einstein relation, the molecular diffusion coefficient is inversely proportional to the viscosity of the matrix that the molecule moves through and inversely proportional to the molecular radius. ${ }^{99,100}$ In pure (dry) shikimic acid for example, $D_{\mathrm{O}_{3}}=2.90 \times 10^{-12} \mathrm{~cm}^{2} \mathrm{~s}^{-1}$, which is 4 orders of magnitude faster than for dry XG/ $/ \mathrm{FeCl}_{2}$ particles. Since $D_{\mathrm{O}_{3}}$ for pure XG is less than for pure shikimic acid, its viscosity should also be higher. It should be noted, however, that for some organic components or when particle viscosity is in excess of $10 \mathrm{~Pa} \mathrm{~s},{ }^{94,101,102}$ the StokesEinstein relation may not necessarily be accurate. Again applying the Stokes-Einstein relation, the viscosity of an aqueous $\mathrm{XG} / \mathrm{FeCl}_{2}$ 
Table 1 Parameters and their units used in the KM-SUB model. Parameter descriptions are found in the ESI

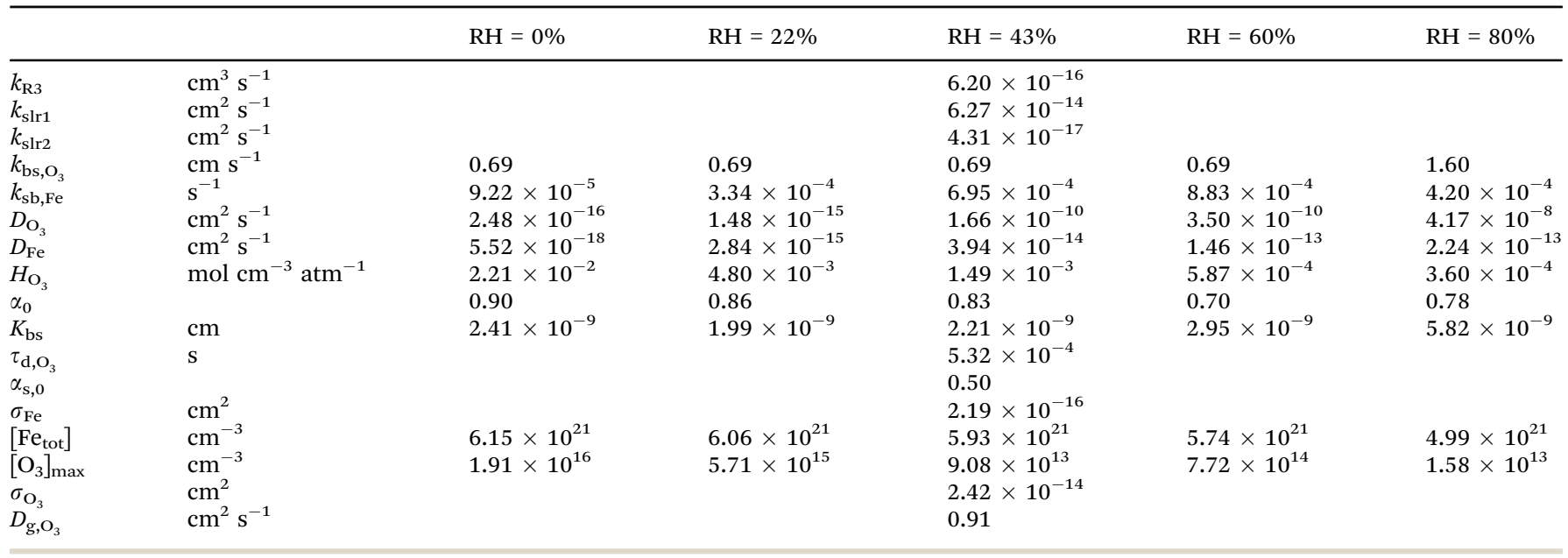

solution at $\mathrm{RH}=80 \%$ should be 3 orders of magnitude less than for water. However, the difference in viscosity of $\mathrm{XG}$ at $\mathrm{RH}=80 \%$ (previously suggested to be glass-like at $10^{13} \mathrm{~Pa} \mathrm{~s}$ ) and water viscosity $\left(10^{-3} \mathrm{~Pa} \mathrm{~s}\right)$ is 16 orders of magnitude. We speculate that this discrepancy may be due to the porous nature of XG, and that pores may have swelled or expanded during water uptake ${ }^{103}$ similar to other hydrogels. ${ }^{104}$ Therefore, $\mathrm{O}_{3}$ mobility may be enhanced in hydrogels that swell compared to what is predicted from the Stokes-Einstein relation.

For iron transport, $D_{\mathrm{Fe}}$ was similar to $D_{\mathrm{O}_{3}}$ at low $\mathrm{RH}$, and a few orders of magnitude less than $D_{\mathrm{O}_{3}}$ at higher RH. Values of $D_{\mathrm{Fe}}$ had a range of about 5 orders of magnitude from dry to $\mathrm{RH}=80 \%$. We note that we have not reported on a selfdiffusion coefficient of $\mathrm{XG}$ in aqueous solution, but it can be found for dilute aqueous solution in previous literature, ${ }^{105}$ e.g. for a $10 \mathrm{~g} \mathrm{~L}^{-1}$ solution (having a water activity $>0.99$ ) attaining $10^{-8} \mathrm{~cm}^{2} \mathrm{~s}^{-1}$ which is about 3 orders of magnitude less than $D_{\mathrm{O}_{3}}^{\circ}$ or $D_{\mathrm{Fe}}^{\circ}$. We suggest that XG self-diffusion coefficients should be less than $D_{\mathrm{O}_{3}}$ or $D_{\mathrm{Fe}}$ at all $\mathrm{RH}$. A caveat of our analysis is that $\mathrm{Fe}^{2+}$ may complex with $\mathrm{XG}^{106,107}$ and therefore, $D_{\mathrm{Fe}}$ may be considered an apparent transport of free ions and those in complex which may have higher and lower diffusion coefficient values, respectively.

In dry XG/FeCl 2 particles, $H_{\mathrm{O}_{3}}=2.21 \times 10^{-2} \mathrm{~mol} \mathrm{~cm}^{-3} \mathrm{~atm}^{-1}$, which is about 3 orders of magnitude higher than for pure water, $H_{\mathrm{O}_{3}}^{\circ}=1.20 \times 10^{-5} \mathrm{~mol} \mathrm{~cm}^{-3} \mathrm{~atm}^{-1}$. Greater solubility of $\mathrm{O}_{3}$ in organic liquids compared to water is well known ${ }^{38,49,93}$ and can be explained by a "salting-in" effect. This is characterized by an increase in the product of ionic strength and activity coefficients of the solution (i.e. decreasing water content) and thus causes an increase in gas solubility. We note that a similar result is found for $\mathrm{O}_{2}$ solubility, which is generally higher in organic liquids than in water. ${ }^{108,109}$ The degree to which activity of $\mathrm{XG} / \mathrm{FeCl}_{2}$ solutions changes as a function of RH is not known. Polymer chains in XG can overlap, aggregate and cross-link ${ }^{105}$ giving rise to anomalous behavior of XG and oxygen diffusion coefficients in aqueous XG solution. ${ }^{105,110}$ It may be possible that our ternary $\mathrm{XG}-\mathrm{FeCl}_{2}$-water system is non-ideal and deviates from ideal mixing. To our knowledge, this is the first report of $\mathrm{O}_{3}$ solubility in XG. In some polymers, $H_{\mathrm{O}_{3}}$ can be greater or less than $H_{\mathrm{O}_{3}}^{\circ}$ such as Hyflon AD80 and Teflon, having $H_{\mathrm{O}_{3}}=1 \times 10^{-4}$ and $4 \times 10^{-6} \mathrm{~mol} \mathrm{~cm}^{-3} \mathrm{~atm}^{-1}$, respectively. In XG/FeCl 2 particles, the optimized $H_{\mathrm{O}_{3}}$ parameter is higher than expected for polymers, and the reason is not yet entirely clear. It may have to do with our optimization and model sensitivity described in the ESI. $\dagger$ We suggest further measurements should be performed in dilute and concentrated XG solutions to understand and quantify $H_{\mathrm{O}_{3}}$ in XG and the trends with $\mathrm{RH}$ and water content.

Fig. 5 shows 3-D profiles of $\alpha$ and $\left[\mathrm{O}_{3}\right]$ normalized to its maximum concentration, $\left[\mathrm{O}_{3}\right]_{\max }$, at each $\mathrm{RH}$ derived from the KM-SUB model. Values of $\left[\mathrm{O}^{3}\right]_{\max }$ are given in Table 1. The 3-D profiles of $\alpha$ in Fig. 5 were used to derive the 2-D derived profiles seen in Fig. 3 (solid lines). Gradients in $\alpha$ at $\mathrm{RH}=0 \%$ (Fig. 5a) spanned a few nanometers, but extended hundreds of nanometers through the particles at $\mathrm{RH}=80 \%$ (Fig. 5i). Despite the extent of gradients in $\alpha, \mathrm{O}_{3}$ was found only in the first picometer to $2.7 \mathrm{~nm}$ at $\mathrm{RH}=0$ to $80 \%$, respectively. We note that a length of $1 \mathrm{pm}$ is much smaller than the molecular scale and the $\mathrm{Fe}^{2+}$ ionic diameter of $0.7 \AA$. However, constraining layer thickness to $0.3 \mathrm{~nm}$ as previously done ${ }^{49}$ could not resolve $\mathrm{O}_{3}$ chemical gradients in our case. We defined layer thickness in KM-SUB without a lower limit to satisfy continuum conditions. This had no consequence, however, because bulk transport follows Fick's Law treating an ensemble of molecules. In general, oxidation reactions can have only taken place where $\mathrm{O}_{3}$ was present at or near the surface of particles, and so gradients in $\alpha$ extending far past $\mathrm{O}_{3}$ penetration depths to nanometers and hundreds of nanometers must have been the result primarily of Fe transport.

\subsection{A case for using a reacto-diffusive framework}

Our observations allowed us to test assumptions for predicting $\alpha$ : the most basic is that our particles were well-mixed for both $\mathrm{Fe}^{2+}$ and $\mathrm{Fe}^{3+}$ and also for $\mathrm{O}_{2}$ and $\mathrm{O}_{3}$ in equilibrium with 

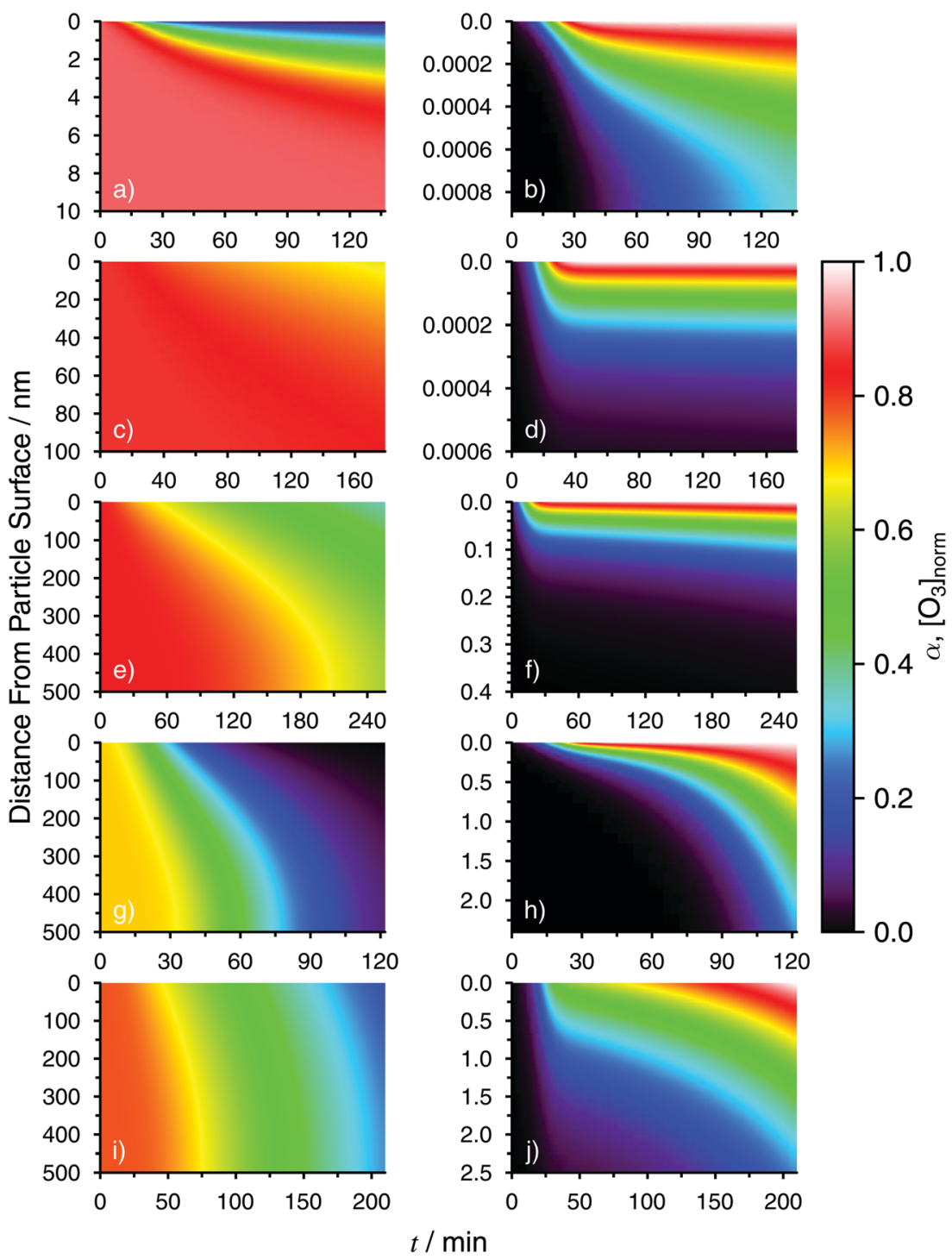

Fig. 5 Model derived 3-D radial profiles of the $\mathrm{Fe}^{2+}$ fraction, $\alpha$ and normalized $\mathrm{O}_{3}$ concentration, $\left[\mathrm{O}_{3}\right]_{\text {norm }}=\left[\mathrm{O}_{3}\right] /\left[\mathrm{O}_{3}\right]_{\text {max }}$, where $\left[\mathrm{O}_{3}\right]_{\text {max }}$ is the maximum $\mathrm{O}_{3}$ concentration for $\mathrm{RH}=0 \%(\mathrm{a}$ and b), 22\% (c and d), 43\% (e and f), 60\% ( $\mathrm{g}$ and $\mathrm{h}$ ) and $80 \%$ ( $\mathrm{i}$ and $\mathrm{j}$ ). The color scale from $0-1$ is the same for both $\alpha$ shown in the left panels $(a, c, e, g$ and $i)$ and $\left[\mathrm{O}_{3}\right]_{\text {norm }}$ shown in the right panels $(b, d, f, h$ and $j)$. The distance from the particle surface is the ordinate. Note that the scales for all panels can be different.

Henry's Law. Oxidation of $\mathrm{Fe}^{2+}$ due to $\mathrm{O}_{2}$ exposure follows the reaction

$$
\mathrm{Fe}^{2+}+\mathrm{O}_{2} \rightarrow \mathrm{Fe}^{3+}+\mathrm{O}_{2}^{\bullet-}
$$

where $k_{\mathrm{R} 4}=0.3 \mathrm{M}^{-1} \mathrm{~s}^{-1}$ taken from previous literature ${ }^{111-114}$ and note that the temperature dependence is negligible for measurements between 20 and $25{ }^{\circ} \mathrm{C}$. Assuming that Henry's Law constant for $\mathrm{O}_{2}$ in water, $H_{\mathrm{O}_{2}}^{\circ}=1.3 \times 10^{-8} \mathrm{M} \mathrm{Pa}^{-1},{ }^{115}$ applies to our $\mathrm{XG} / \mathrm{FeCl}_{2}$ with a $\mathrm{O}_{2}$ partial pressure of $30 \mathrm{mbar}$ (for the PolLux environmental microreactor at a total pressure of 150 mbar), the equilibrium condensed phase $\mathrm{O}_{2}$ concentration was $3.9 \times 10^{-5} \mathrm{M}$. Then, the first order loss rate for $\mathrm{Fe}^{2+}$, $k^{I}$, in reaction $\mathrm{R} 4$ is $k_{\mathrm{R} 4}^{I}=1.2 \times 10^{-5} \mathrm{~s}^{-1}$. We compare this to $k^{I}=1.6 \times 10^{-2} \mathrm{~s}^{-1}$ calculated using $H_{\mathrm{O}_{3}}^{\circ}$ for water ${ }^{115}$ and $\left[\mathrm{O}_{3}\right]_{\mathrm{g}}=150$ ppb or 0.015 Pa partial pressure. Since $k_{\mathrm{R} 3}^{I}$ is 3 orders of magnitude larger than $k_{\mathrm{R} 4}^{I}$, it comes as no surprise that to achieve a similar decay of $\alpha$ due to $\mathrm{O}_{3}$ observed over hours, an experiment with only $\mathrm{O}_{2}$ would need to last thousands of hours longer. This is consistent with our finding that $\mathrm{O}_{2}$ reaction in our system is negligible. Applying $k_{\mathrm{R} 4}^{I}=1.2 \times 10^{-5} \mathrm{~s}^{-1}$, we calculate the loss of $\alpha=\alpha_{0} \exp \left(k_{\mathrm{R} 4}^{I} t\right)$. After $t=2 \mathrm{~h}, \alpha$ would be depleted by $8 \%$. Using $k_{\mathrm{R} 3}^{I}, \alpha$ would be $100 \%$ depleted. Clearly, this is in disagreement with our observations. If XG acted as a ligand for $\mathrm{Fe}^{2+}$, this may change the rate of reaction and whether reaction rates are enhanced or reduced may depend on the specific system involved. A previous study ${ }^{114}$ found that rate coefficients of $\mathrm{O}_{2}$ with a $\mathrm{Fe}^{2+}$-fulvic acid complex was $100 \mathrm{M}^{-1} \mathrm{~s}^{-1}$, which is over 100 times greater than $k_{\mathrm{R} 4}^{I}$. Another previous study found that iron oxidation with $\mathrm{OH}, \mathrm{H}_{2} \mathrm{O}_{2}$ and $\mathrm{HO}_{2}$ was observed to 
be only 3 times higher with humic acid ligands from waste water than without. ${ }^{116}$ In contrast, it was found that iron in steel was complexed with XG in dilute solution and that oxidation and corrosion due to $\mathrm{HCl}$ was inhibited ${ }^{107}$ implying a reduction in reaction rate. Due to a lack of observations of $\mathrm{O}_{3}$ oxidation of xanthan gum ligands with $\mathrm{Fe}$, we maintain our choice of $k_{\mathrm{R} 3}$, and argue decreasing molecular transport of $\mathrm{Fe}$ and $\mathrm{O}_{3}$ leads to a significant decrease in the loss rate of $\mathrm{Fe}^{2+}$ far lower than expected when considering particles are well-mixed and in Henry's Law equilibrium.

We test the applicability of a reacto-diffusive framework described in Steimer et $a l^{38}$ to predict ozone transport and reaction into our particles. This is an analytical solution to the chemical loss as a function of $t$, which assumes that $\mathrm{O}_{3}$ reaction occurs in a thin shell or over a much smaller length scale than the particle diameter and that $\mathrm{Fe}^{2+}$ is homogeneously mixed. Following Steimer et al. ${ }^{38}$ the time rate of change of $\alpha$ is written as

$$
\frac{\mathrm{d} \alpha}{\mathrm{d} t}=-k^{\mathrm{D}} \sqrt{\frac{\alpha}{\left[\mathrm{Fe}_{\mathrm{tot}}\right]}},
$$

where

$$
k^{\mathrm{D}}=-H_{\mathrm{O}_{3}}\left[\mathrm{O}_{3}\right]_{\mathrm{g}} R T_{\mathrm{p}} \sqrt{D_{\mathrm{O}_{3}} k_{\mathrm{R} 3}} \frac{6}{d_{\mathrm{p}}},
$$

is the reacto-diffusive rate constant, ${ }^{38} R$ is the universal gas constant, and $6 / d_{\mathrm{p}}$ is the surface to volume ratio of our particles assuming they are half spheres. Substituting eqn (3) into (2) and rearranging gives the following relationship

$$
\frac{d_{\mathrm{p}}}{3 R T_{\mathrm{p}}} \frac{\left[\mathrm{Fe}_{\mathrm{tot}}\right]\left(\sqrt{\alpha}-\sqrt{\alpha_{\circ}}\right)}{\phi(t) \sqrt{k_{\mathrm{R} 3}}}=H_{\mathrm{O}_{3}} \sqrt{D_{\mathrm{O}_{3}}}
$$

The left hand side of eqn (4) is entirely dependent on measurable and available quantities while the right hand side is in terms of the fitted parameters used in KM-SUB. Therefore, this provides a point of comparison to evaluate the suitability of the reacto-diffusive framework to predict Fe oxidation reaction and can be calculated for each individually probed particle. Fig. 6 shows a box plot of experimentally derived $H_{\mathrm{O}_{3}} \sqrt{D_{\mathrm{O}_{3}}}$ for all particles investigated as a function of $\mathrm{RH}$. The median and quartile range of $H_{\mathrm{O}_{3}} \sqrt{D_{\mathrm{O}_{3}}}$ values for thousands of particles are shown. Values for individual particles are shown in Fig. S12 in the ESI. $\dagger$ Also included in Fig. 6 is the value of $H_{\mathrm{O}_{3}} \sqrt{D_{\mathrm{O}_{3}}}$ derived using optimized parameters from the KM-SUB model for comparison. The 25 and 75 percentiles of $H_{\mathrm{O}_{3}} \sqrt{D_{\mathrm{O}_{3}}}$ data capture the values of the fitting parameters from KM-SUB (Table 1). Median values are indicated by a horizontal solid line within the boxes. It is important to note that for some particles, mainly those investigated within minutes of the start of reaction, depletion of $\alpha$ is small and scatters around $\alpha_{0}$. This leads to negative values of $\sqrt{\alpha}-\sqrt{\alpha_{0}}$ and thus negative values of $H_{\mathrm{O}_{3}} \sqrt{D_{\mathrm{O}_{3}}}$ (see Fig. S12 in the ESI $\dagger$ ), which is physically unrealistic. However, we choose to include these in Fig. S12 (ESI $\dagger$ ) as they contribute to the scatter in our data. If a data point falls outside of three times the median absolute deviation, it is

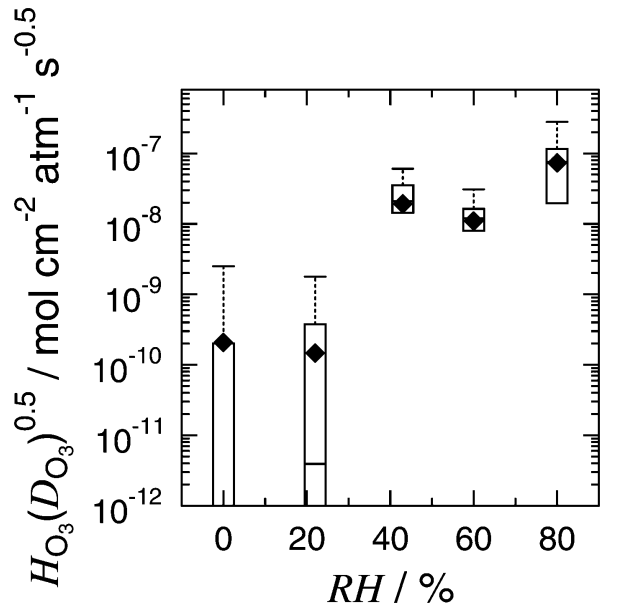

Fig. 6 A box plot of the product of Henry's Law constant for ozone, $H_{\mathrm{O}^{\prime}}$ and the square root of the diffusion coefficient of ozone, $D_{\mathrm{O}_{3^{\prime}}}$ or $H_{\mathrm{O}_{3}} \sqrt{D_{\mathrm{O}_{3}}}$ as a function of $\mathrm{RH}$. The bottom and top of the boxes represent 25 and 75 percentiles of about 1550 particles. Horizontal lines within boxes are median values. Upper error bars indicate $3 \times$ the median absolute deviation (MAD). The lower $3 \times$ MAD interval extends to negative values, and thus lower error bars are not depicted. All data for individual particles is shown in Fig. S12 (ESI $)$. Solid diamonds are derived from fitted parameters in Table 1.

considered an outlier and shown as a symbol with a cross in Fig. S12 (ESI $\dagger$ ).

Direct comparison of data and model (eqn (4)) validate the use of the reacto-diffusive framework. An important feature of eqn (2) and (3) is that $D_{\mathrm{Fe}}$ is not required, because reactodiffusive framework assumes a homogeneous distribution in $\alpha$. Despite that we observed chemical gradients (Fig. 3), this assumption is "good enough" within our experimental conditions due to agreement in Fig. 6. We rearrange eqn (4) to calculate $\alpha(t)$ following

$$
\alpha(t)=\left(\sqrt{\alpha_{\mathrm{o}}}-\frac{3\left(H_{\mathrm{O}_{3}} \sqrt{D_{\mathrm{O}_{3}}}\right) R T_{\mathrm{p}} \sqrt{k_{\mathrm{R} 3}} \phi(t)}{\sqrt{\left[\mathrm{Fe}_{\mathrm{tot}}\right]} d_{\mathrm{p}}}\right)^{2},
$$

shown in Fig. 2 as dotted lines, where the shading represents the quartile range of observed $H_{\mathrm{O}_{3}} \sqrt{D_{\mathrm{O}_{3}}}$ and using the geometric mean of $d_{\mathrm{p}}$ respective to each experiment. We note that eqn (5) used only our observations and no fitted parameters. There is generally good agreement between our data, the reactodiffusive framework and the KM-SUB model considering all uncertainties. At $\mathrm{RH}=0$ and $20 \%$, there is a significant data scatter and the 25th percentile level goes below zero. It is important to note that the product $H_{\mathrm{O}_{3}} \sqrt{D_{\mathrm{O}_{3}}}$ should not depend on particle surface to volume ratio (Fig. S12 in the ESI $\dagger$ ) if the reacto-diffusive framework is valid. This was generally the case for all $\mathrm{RH}$ within the scatter of our data, expect for experiments at $\mathrm{RH}=60 \%$ when $\left[\mathrm{O}_{3}\right]$ was relatively high and $\alpha$ approached close to zero. Eqn (5) does not take into account all size dependent factors ${ }^{117,118}$ and will miss out on those induced by the diffusion limitation of Fe. This may lead to an over-prediction of the decay of $\alpha$ by the reacto-diffusive framework. For example, the lifetime of $\mathrm{Fe}^{2+}$ calculated using 
the reacto-diffusive framework is about 22 and 3 times shorter than for KM-SUB at $\mathrm{RH}=0$ and $80 \%$, respectively, using the same parameters as in Table 1 and constant $\left[\mathrm{O}_{3}\right]_{\mathrm{g}}=50 \mathrm{ppb}$. Eqn (3) describes how, in the reacto-diffusive regime, the rate constant is inversely dependent on $d_{\mathrm{p}}$. Increasing or decreasing the modeled $d_{\mathrm{p}}$ from $1 \mu \mathrm{m}$ will tend to over or under predict $\alpha$, respectively. In other words, particles that are expanding due to water uptake would appear to have a lower rate of iron oxidation. Note that the model employs a fixed $d_{\mathrm{p}}$ at different $\mathrm{RH}$ and thus corresponds to effectively different dry diameters. The same applies to the experiment, due to the fact that different particles are probed at each time (a different field of view) under different RH. A new random population of particles is imaged at each time point. These humidity effects should not significantly affect our parameter optimization because the scatter of our data shown in Fig. S12 (ESI $\dagger$ ) is generally larger than effects due to particle size. The vast number of particles and the high time resolution used in our observation ensures enough data is available to effectively conclude that the reactodiffusive framework is an acceptable approximation for the KMSUB model to describe $\mathrm{O}_{3}$ oxidation in our experiments.

We argue that a reacto-diffusive limitation may apply to $\mathrm{O}_{2}$ as it does for $\mathrm{O}_{3}$. We observed no loss of $\mathrm{Fe}^{2+}$ during $\mathrm{O}_{2}$ exposure over hours. At $\mathrm{RH}=80 \%, \alpha_{0}=0.78$, and $2-4$ hours of $\mathrm{O}_{2}$ reaction assuming homogeneous mixing of both $\mathrm{O}_{2}$ and $\mathrm{Fe}^{2+}$ would result in $\alpha=0.71-0.65$. We should have been able to observe this decay considering our uncertainty in $\alpha$, especially when using a three times higher $\mathrm{O}_{2}$ particle pressure for experiments at $\mathrm{RH}=0 \%, 20 \%$ and $60 \%$. Assuming that $D_{\mathrm{O}_{2}}$ was identical to that of $D_{\mathrm{O}_{3}}$, we determined the reacto-diffusive length scale, $l_{\mathrm{rd}}=\sqrt{D_{\mathrm{O}_{2}} /\left(\alpha_{0}\left[\mathrm{Fe}_{\mathrm{tot}}\right] k_{\mathrm{R} 4}\right)}$, at dry conditions and $\mathrm{RH}=80 \%$ for $\mathrm{O}_{2}$ on the order of $0.1 \mathrm{~nm}$ to $1 \mu \mathrm{m}$. These estimates indicate that $\mathrm{O}_{2}$ reaction may have also been diffusion limited similar to $\mathrm{O}_{3}$. However, to fully evaluate this, time scales of days would be required to study $\mathrm{O}_{2}$ transport and reaction in this system.

Our findings that $\mathrm{O}_{3}$ reaction is diffusion limited led us to speculate that other condensed phase reactions involving organic species can also be slowed due to low diffusion coefficients. There is increasing evidence that predicting secondary organic aerosol (SOA) mass must take into account condensed phase chemical reactions that include in part, oligomerization or acid catalyzed and accretion reactions that significantly increase molecular weight, reduce re-evaporation of organic compounds to the gas phase and thus add to the total mass of SOA. ${ }^{11,13,119,120}$ Examples of these are glyoxal uptake and reaction, ${ }^{121}$ oligomerization of volatile condensed phase molecules, ${ }^{122}$ aldol condensation and esterification. $^{20,123}$ Isoprene epoxydiols (IEPOX) are major gas phase products of isoprene oxidation that are highly soluble and reactive in the condensed phase. ${ }^{11,13}$ When depleted in the condensed phase due to chemical reaction there, a net reactive uptake of IEPOX has been shown to lead to increasing organic and organosulfate formation contributing significantly to aqueous SOA mass in atmospheric environments. ${ }^{124}$ However, Zhang et al. ${ }^{125}$ showed in a laboratory study that when organic coatings were present on acidic aerosol particles, IEPOX reactive uptake decreased as coating thicknesses increased up to $32 \mathrm{~nm}$ and when $\mathrm{RH}$ was decreased from $50-15 \%$. We speculate that irreversible uptake of IEPOX may also be diffusion limited. In general, diffusion limitations slow reactions compared to predictions considering homogeneous mixing and equilibrium with Henry's Law. For this reason, we suggest that aerosol chemical studies should be evaluated with the reacto-diffusive framework described here and in previous work ${ }^{38,117,118}$ to test its predictive capability under a range of atmospheric conditions. We call for a database of diffusion coefficients and Henry's Law constants applicable for oxidants and reactants in highly concentrated aerosol particles. ${ }^{94}$ This would preferably be for a wide range of temperature and humidity and for materials such as secondary organic aerosol and their proxies. ${ }^{16}$ Doing so would allow further evaluation of when reaction and diffusion limitations apply and elucidate how pervasive they are to atmospheric multi-phase chemistry.

\section{Conclusions}

We have measured chemical gradients within individual aerosol particles containing xanthan gum and $\mathrm{FeCl}_{2}$ due to heterogeneous reaction with $\mathrm{O}_{3}$. Oxidation from $\mathrm{Fe}^{2+}$ to $\mathrm{Fe}^{3+}$ was imaged in 2-D using STXM/NEXAFS prior to and during in situ $\mathrm{O}_{3}$ exposure for hours. Using a novel 2-D concentric perimeter analysis and careful error propagation, we were able to derive 2-D reaction profiles with well-defined uncertainties. Thousands of particles were probed, each with hundreds of pixels that provided quantitative spatial and chemical information about the reaction with $\mathrm{O}_{3}$. We found that during $\mathrm{O}_{3}$ exposure, increased oxidation occurred with increasing $\mathrm{RH}$ and $\left[\mathrm{O}_{3}\right]_{\mathrm{g}}$. At all reaction time and at particle perimeters, i.e. the outer most pixels of all particles, $\alpha$ was consistently less than concentric pixels toward the particle center. Therefore, we conclude that $\mathrm{O}_{3}$ oxidized particle surfaces more than interiors. Observed 2-D gradients in $\alpha$ from perimeter to center were shallow and ranged roughly by about 0.2 over the first $200 \mathrm{~nm}$ at $\mathrm{RH}=0$ and $22 \%$. At $\mathrm{RH}=43,60$ and $80 \%$, a difference of 0.2 in $\alpha$ occurred for $\geq 500 \mathrm{~nm}$. We conclude that changes in $\mathrm{O}_{3}$ and Fe transport must have occurred and were driven by the water content in xanthan gum, which is known to increase with increasing $\mathrm{RH}$. To test this conclusion, we used the kinetic multi-layer model for aerosol surface and bulk chemistry, KM-SUB. Using previous literature values where possible and fitting parameters for diffusion coefficients of $\mathrm{O}_{3}$ and $\mathrm{Fe}^{2+}$, as well as Henry's Law constants for $\mathrm{O}_{3}$ as a function of $\mathrm{RH}$, we were able to predict 2-D concentration profiles. This is the first time that a direct comparison between observed and predicted internal aerosol spatio-chemical changes has been achieved. Resulting diffusion coefficients increased exponentially as a function of $\mathrm{RH}$ and was parameterized using a Vignes-type equation. $\mathrm{H}_{\mathrm{O}_{3}}$ decreased exponentially as a function of $\mathrm{RH}$ and could also be described using a Vignes-type equation. A volume mixing rule over-predicted $H_{\mathrm{O}_{3}}$ and is advised not to be used for 
this system. Our findings may apply for ozone in marine derived organic aerosol due to XG being a proxy of polysaccharide and exopolymer particles found to be aerosolized from oceans.

We have used a limiting case in heterogeneous aerosol chemistry referred to as a reacto-diffusive kinetic regime to describe our results following a square root dependent loss rate of $\alpha$. The corresponding framework described oxidation by $\mathrm{O}_{3}$ to occur in a thin layer at the aerosol surface with uniformly distributed (or well-mixed) condensed phase $\mathrm{Fe}^{2+}$ concentration in the bulk. However, this was not supported because shallow gradients in $\mathrm{Fe}^{2+}$ were, in fact, observed. Despite this, we tested the appropriateness of this approximation using only observed values to derive the product of the Henry's Law constant and the square root of the diffusion coefficient for $\mathrm{O}_{3}$, or $H_{\mathrm{O}_{3}} \sqrt{D_{\mathrm{O}_{3}}}$, at all experimental conditions. This product could be directly compared with those derived from KM-SUB. It was found that within experimental uncertainties, total depletion of $\mathrm{Fe}^{2+}$ could be reproduced for all experiments, and we conclude that the reacto-diffusive framework was applicable to describe the chemical gradients observed here. This approximation makes predicting the loss rate of aerosol components significantly easier with no computational expense compared to the KM-SUB or any other multilayer reaction and diffusion models. Furthermore, important chemical and physical parameters in the reacto-diffusive framework such as diffusion coefficients, Henry's Law constants, and second order bulk reaction rates are currently capable of being derived in a laboratory setting or a controlled setting in the ambient atmosphere. We have derived these parameters for $\mathrm{O}_{3}$ and Fe using KM-SUB in xanthan gum, a proxy for a natural biogenic source of organic matter emitted directly into the marine atmosphere. Their use should give better representation of condensed phase loss and production rates of reactants and products in marine aerosol with $\mathrm{O}_{3}$. Furthermore, we also suggest that the reacto-diffusive framework should be evaluated for various oxidants and reactants under a wide range of temperature and humidity to further validate its use in atmospheric heterogeneous chemical reactions.

\section{Author contributions}

P. A. A. envisioned this project, conducted experiments, performed data analysis, modeled results and wrote the paper. P. A. A. and M. A. oversaw the entire project. P. C. A., J. D., S. S. S., J.-D. F., F. D., S. R., M. P. and S. P. acquired data and performed data analysis. M. S. and T. B. wrote the KM-SUB model and evaluated model results. T. B. supervised the modeling process. B. W. evaluated data analysis and maintained operation of experiment. U. K. K., C. P., C. G., M. S., B. W. and M. A. supervised the project. All authors contributed to the writing of the manuscript.

\section{Conflicts of interest}

We declare no conflict of interest.

\section{Acknowledgements}

This work was funded by the Swiss National Science Foundation (Grant 163074) and by the European Union's Horizon 2020 research and innovation program under the Marie SkodowskaCurie grant agreement (No 701647). J.-D. F., F. D. and C. P. acknowledge support by the Max Planck Society. P. A. A., S. R., M. P., S. P. and C. G. received support from the European Research Council under the European Union's Seventh Framework Program (FP/2007-2013)/ERC Grant Agreement (290852AIRSEA). M. S. acknowledges funding from the National Science Foundation (AGS-1654104). T. B. acknowledges support by the Eckert Postdoctoral Fellowship from Georgia Tech School of Chemical and Biomolecular Engineering. The PolLux end station was financed by the German Ministerium für Bildung und Forschung (BMBF) through contracts 05KS4WE1/6 and 05KS7WE1.

\section{References}

1 Q. Zhang, J. L. Jimenez, M. R. Canagaratna, J. D. Allan, H. Coe, I. Ulbrich, M. R. Alfarra, A. Takami, A. M. Middlebrook, Y. L. Sun, K. Dzepina, E. Dunlea, K. Docherty, P. F. DeCarlo, D. Salcedo, T. Onasch, J. T. Jayne, T. Miyoshi, A. Shimono, S. Hatakeyama, N. Takegawa, Y. Kondo, J. Schneider, F. Drewnick, S. Borrmann, S. Weimer, K. Demerjian, P. Williams, K. Bower, R. Bahreini, L. Cottrell, R. J. Griffin, J. Rautiainen, J. Y. Sun, Y. M. Zhang and D. R. Worsnop, Geophys. Res. Lett., 2007, 34, L13801.

2 L. M. Russell, L. N. Hawkins, A. A. Frossard, P. K. Quinn and T. S. Bates, Proc. Natl. Acad. Sci. U. S. A., 2010, 107, 6652-6657.

3 A. Laskin, M. K. Gilles, D. A. Knopf, B. Wang and S. China, Annu. Rev. Anal. Chem., 2016, 9, 117-143.

4 J. Haywood and O. Boucher, Rev. Geophys., 2000, 38, 513-543.

5 O. Boucher, D. Randall, P. Artaxo, C. Bretherton, G. Feingold, P. Forster, V.-M. Kerminen, Y. Kondo, H. Liao, U. Lohmann, P. Rasch, S. K. Satheesh, S. Sherwood, S. B. and Z. X.-Y., in Climate Change 2013: The Physical Science Basis. Contribution of Working Group I to the Fifth Assessment Report of the Intergovernmental Panel on Climate Change, ed. S. Fuzzi, J. Penner, V. Ramaswamy and C. Stubenrauch, Cambridge University Press, Cambridge, United Kingdom and New York, NY, USA, 2013, ch. 8, Clouds and Aerosols, pp. 571-657.

6 T. Storelvmo, Annu. Rev. Earth Planet. Sci., 2017, 45, 199-222.

7 D. A. Knopf, P. A. Alpert and B. Wang, ACS Earth Space Chem., 2018, 2, 168-202.

8 Z. A. Kanji, L. A. Ladino, H. Wex, Y. Boose, M. Burkert-Kohn, D. J. Cziczo and M. Krämer, Meteor. Mon., 2017, 58, 1.1-1.33.

9 J. H. Seinfeld and S. N. Pandis, Atmospheric Chemistry and Physics - From Air Pollution to Climate Change, John Wiley \& Sons., Hoboken, NJ, 2nd edn, 2006.

10 A. Tilgner, P. Bräuer, R. Wolke and H. Herrmann, J. Atmos. Chem., 2013, 70, 221-256.

11 H. Herrmann, T. Schaefer, A. Tilgner, S. A. Styler, C. Weller, M. Teich and T. Otto, Chem. Rev., 2015, 115, 4259-4334. 
12 B. Ervens, in Multiphase Environmental Chemistry in the Atmosphere, ed. S. W. Hunt, A. Laskin and S. A. Nizkorodov, American Chemical Society, Washington, DC, 2018, ch. Progress and problems in modeling chemical processing in cloud droplets and wet aerosol particles, pp. 327-345.

13 M. Shrivastava, S. Lou, A. Zelenyuk, R. C. Easter, R. A. Corley, B. D. Thrall, P. J. Rasch, J. D. Fast, S. L. Massey Simonich, H. Shen and S. Tao, Proc. Natl. Acad. Sci. U. S. A., 2017, 114, 1246-1251.

14 D. K. Farmer, C. D. Cappa and S. M. Kreidenweis, Chem. Rev., 2015, 115, 4199-4217.

15 A. Laskin, R. C. Moffet, M. K. Gilles, J. D. Fast, R. A. Zaveri, B. Wang, P. Nigge and J. Shutthanandan, J. Geophys. Res., 2012, 117, D15302.

16 M. Shiraiwa, Y. Li, A. P. Tsimpidi, V. A. Karydis, T. Berkemeier, S. N. Pandis, J. Lelieveld, T. Koop and U. Pöschl, Nat. Commun., 2017, 8, 15002.

17 J. P. Reid, A. K. Bertram, D. O. Topping, A. Laskin, S. T. Martin, M. D. Petters, F. D. Pope and G. Rovelli, Nat. Commun., 2018, 9, 15002.

18 B. R. Bzdek and J. P. Reid, J. Chem. Phys., 2017, 147, 220901. 19 V. Perraud, E. A. Bruns, M. J. Ezell, S. N. Johnson, Y. Yu, M. L. Alexander, A. Zelenyuk, D. Imre, W. L. Chang, D. Dabdub, J. F. Pankow and B. J. Finlayson-Pitts, Proc. Natl. Acad. Sci. U. S. A., 2012, 109, 2836-2841.

20 M. Shiraiwa, L. D. Yee, K. A. Schilling, C. L. Loza, J. S. Craven, A. Zuend, P. J. Ziemann and J. H. Seinfeld, Proc. Natl. Acad. Sci. U. S. A., 2013, 110, 11746-11750.

21 L. Renbaum-Wolff, J. W. Grayson, A. P. Bateman, M. Kuwata, M. Sellier, B. J. Murray, J. E. Shilling, S. T. Martin and A. K. Bertram, Proc. Natl. Acad. Sci. U. S. A., 2013, 110, 8014-8019.

22 M. Kuwata and S. T. Martin, Proc. Natl. Acad. Sci. U. S. A., 2012, 109, 17354-17359.

23 J. H. Slade and D. A. Knopf, Geophys. Res. Lett., 2014, 41, 5297-5306.

24 J. Socorro, P. S. J. Lakey, L. Han, T. Berkemeier, G. Lammel, C. Zetzsch, U. Pöschl and M. Shiraiwa, Environ. Sci. Technol., 2017, 51, 13749-13754.

25 J. D. Smith, J. H. Kroll, C. D. Cappa, D. L. Che, C. L. Liu, M. Ahmed, S. R. Leone, D. R. Worsnop and K. R. Wilson, Atmos. Chem. Phys., 2009, 9, 3209-3222.

26 M. N. Chan, H. Zhang, A. H. Goldstein and K. R. Wilson, J. Phys. Chem. C, 2014, 118, 28978-28992.

27 A. M. Arangio, J. H. Slade, T. Berkemeier, U. Pöschl, D. A. Knopf and M. Shiraiwa, J. Phys. Chem. A, 2015, 119, 4533-4544.

28 J. F. Davies and K. R. Wilson, Chem. Sci., 2015, 6, 7020-7027.

29 H. Fan, M. R. Tinsley and F. Goulay, J. Phys. Chem. A, 2015, 119, 11182-11190.

30 M. M. Chim, C. T. Cheng, J. F. Davies, T. Berkemeier, M. Shiraiwa, A. Zuend and M. N. Chan, Atmos. Chem. Phys., 2017, 17, 14415-14431.

31 M. M. Chim, C. Y. Chow, J. F. Davies and M. N. Chan, J. Phys. Chem. A, 2017, 121, 1666-1674.
32 M. J. Liu, A. A. Wiegel, K. R. Wilson and F. A. Houle, J. Phys. Chem. A, 2017, 121, 5856-5870.

33 K. C. Kwong, M. M. Chim, E. H. Hoffmann, A. Tilgner, H. Herrmann, J. F. Davies, K. R. Wilson and M. N. Chan, ACS Earth Space Chem., 2018, 2, 895-903.

34 M. M. Chim, C. Y. Lim, J. H. Kroll and M. N. Chan, ACS Earth Space Chem., 2018, 2, 1323-1329.

35 Z. Li, K. A. Smith and C. D. Cappa, Atmos. Chem. Phys., 2018, 18, 14585-14608.

36 M. Shiraiwa, M. Ammann, T. Koop and U. Pöschl, Proc. Natl. Acad. Sci. U. S. A., 2011, 108, 11003-11008.

37 S. Zhou, M. Shiraiwa, R. D. McWhinney, U. Pöschl and J. P. D. Abbatt, Faraday Discuss., 2013, 165, 391-406.

38 S. S. Steimer, M. Lampimäki, E. Coz, G. Grzinic and M. Ammann, Atmos. Chem. Phys., 2014, 14, 10761-10772.

39 S. S. Steimer, T. Berkemeier, A. Gilgen, U. K. Krieger, T. Peter, M. Shiraiwa and M. Ammann, Phys. Chem. Chem. Phys., 2015, 17, 31101-31109.

40 M. I. Jacobs, B. Xu, O. Kostko, N. Heine, M. Ahmed and K. R. Wilson, J. Phys. Chem. A, 2016, 120, 8645-8656.

41 N. Heine, F. A. Houle and K. R. Wilson, Environ. Sci. Technol., 2017, 51, 13740-13748.

42 U. Pöschl, Y. Rudich and M. Ammann, Atmos. Chem. Phys, 2007, 7, 5989-6023.

43 M. Ammann and U. Pöschl, Atmos. Chem. Phys., 2007, 7, 6025-6045.

44 C. Pfrang, M. Shiraiwa and U. Pöschl, Atmos. Chem. Phys., 2010, 10, 4537-4557.

45 M. Shiraiwa, C. Pfrang and U. Pöschl, Atmos. Chem. Phys., 2010, 10, 3673-3691.

46 M. Shiraiwa, C. Pfrang, T. Koop and U. Pöschl, Atmos. Chem. Phys., 2012, 12, 2777-2794.

47 T. Berkemeier, A. J. Huisman, M. Ammann, M. Shiraiwa, T. Koop and U. Pöschl, Atmos. Chem. Phys., 2013, 13, 6663-6686.

48 F. A. Houle, W. D. Hinsberg and K. R. Wilson, Phys. Chem. Chem. Phys., 2015, 17, 4412-4423.

49 T. Berkemeier, S. S. Steimer, U. K. Krieger, T. Peter, U. Pöschl, M. Ammann and M. Shiraiwa, Phys. Chem. Chem. Phys., 2016, 18, 12662-12674.

50 A. A. Wiegel, M. J. Liu, W. D. Hinsberg, K. R. Wilson and F. A. Houle, Phys. Chem. Chem. Phys., 2017, 19, 6814-6830.

51 F. A. Houle, A. A. Wiegel and K. R. Wilson, Environ. Sci. Technol., 2018, 52, 13774-13781.

52 F. A. Houle, A. A. Wiegel and K. R. Wilson, J. Phys. Chem. Lett., 2018, 9, 1053-1057.

53 C. A. Angell, Science, 1995, 267, 1924-1935.

54 P. G. Debenedetti and F. H. Stillinger, Nature, 2001, 410, 259-267.

55 T. Koop, J. Bookhold, M. Shiraiwa and U. Pöschl, Phys. Chem. Chem. Phys., 2011, 13, 19238-19255.

56 L. Lee and K. Wilson, J. Phys. Chem. A, 2016, 120, 6800-6812.

57 T. J. Conocchioli, E. J. Hamilton and N. Sutin, J. Am. Chem. Soc., 1965, 87, 926-927.

58 J. Hoigné, H. Bader, W. Haag and J. Staehelin, Water Res., 1985, 19, 993-1004. 
59 T. Løegager, J. Holcman, K. Sehested and T. Pedersen, Inorg. Chem., 1992, 31, 3523-3529.

60 O. Pestovsky and A. Bakac, Inorg. Chem., 2006, 45, 814-820.

61 S. Enami, Y. Sakamoto and A. J. Colussi, Proc. Natl. Acad. Sci. U. S. A., 2014, 111, 623-628.

62 R. C. Moffet, H. Furutani, T. C. Rödel, T. R. Henn, P. O. Sprau, A. Laskin, M. Uematsu and M. K. Gilles, J. Geophys. Res., 2012, 117, D07204.

63 S. Stohs and D. Bagchi, Free Radical Biol. Med., 1995, 18, 321-336.

64 N. Li, C. Sioutas, A. Cho, D. Schmitz, C. Misra, J. Sempf, M. Wang, T. Oberley, J. Froines and A. Nel, Environ. Health Persp., 2003, 111, 455-460.

65 M. Shiraiwa, K. Selzle and U. Pöschl, Free Radical Res., 2012, 46, 927-939.

66 H. Tong, P. S. J. Lakey, A. M. Arangio, J. Socorro, C. J. Kampf, T. Berkemeier, W. H. Brune, U. Pöschl and M. Shiraiwa, Faraday Discuss., 2017, 200, 251-270.

67 T. D. Jickells, Z. S. An, K. K. Andersen, A. R. Baker, G. Bergametti, N. Brooks, J. J. Cao, P. W. Boyd, R. A. Duce, K. A. Hunter, H. Kawahata, N. Kubilay, J. laRoche, P. S. Liss, N. Mahowald, J. M. Prospero, A. J. Ridgwell, I. Tegen and R. Torres, Science, 2005, 308, 67-71.

68 M. T. Maldonado and N. M. Price, Deep-Sea Res. Pt. II, 1999, 46, 2447-2473.

69 A. Baker and P. Croot, Mar. Chem., 2010, 120, 4-13.

70 Z. Shi, M. D. Krom, T. D. Jickells, S. Bonneville, K. S. Carslaw, N. Mihalopoulos, A. R. Baker and L. G. Benning, Aeolian Res., 2012, 5, 21-42.

71 H. Chen and V. H. Grassian, Environ. Sci. Technol., 2013, 47, 10312-10321.

72 R. Paris and K. V. Desboeufs, Atmos. Chem. Phys., 2013, 13, 4895-4905.

73 A. Ito and Z. Shi, Atmos. Chem. Phys., 2016, 16, 85-99.

74 N. M. Mahowald, R. Scanza, J. Brahney, C. L. Goodale, P. G. Hess, J. K. Moore and J. Neff, Curr. Clim. Change Rep., 2017, 3, 16-31.

75 M. Kanakidou, S. Myriokefalitakis and K. Tsigaridis, Environ. Res. Lett., 2018, 13, 063004.

76 K. W. Dawson, M. D. Petters, N. Meskhidze, S. S. Petters and S. M. Kreidenweis, J. Geophys. Res., 2016, 121, 11803-11818.

77 I. A. Challen, in Food Hydrocolloids: Structures, Properties, and Functions, ed. K. Nishinari and E. Doi, Plenum Press, New York, NY, USA, 1993, ch. Xanthan Gum: A Multifunctional Stabiliser for Food Products, pp. 135-140.

78 B. Katzbauer, Polym. Degrad. Stab., 1998, 59, 81-84.

79 S. Basu, U. S. Shivhare and A. S. Mujumdar, Dry. Technol., 2007, 25, 1581-1586.

80 U. Passow and A. L. Alldredge, Limnol. Oceanogr., 1995, 40, 1326-1335.

81 U. Passow, Prog. Oceanogr., 2002, 55, 287-333.

82 A. Engel, in Practical Guidelines for the Analysis of Seawater, ed. O. Wurl, CRC Press, Boca Raton, FL, USA, 2009, ch. 7. Determination of Marine Gel Particles, pp. 125-142.

83 J. Y. Aller, J. C. Radway, W. P. Kilthau, D. W. Bothe, T. W. Wilson, R. D. Vaillancourt, P. K. Quinn, D. J. Coffman,
B. J. Murray and D. A. Knopf, Atmos. Environ., 2017, 154, 331-347.

84 T. Huthwelker, V. Zelenay, M. Birrer, A. Krepelova, J. Raabe, G. Tzvetkov, M. G. C. Vernooij and M. Ammann, Rev. Sci. Instrum., 2010, 81, 113706.

85 J.-D. Förster, C. Pöhlker, C. Gurk, M. Lamneck, M. Ammann, U. Pöschl and M. O. Andreae, Atmos. Mech. Tech., 2019, to be submitted.

86 D. M. Murphy and T. Koop, Q. J. R. Meteorol. Soc., 2005, 131, 1539-1565.

87 J. Raabe, G. Tzvetkov, U. Flechsig, M. Böge, A. Jaggi, B. Sarafimov, M. G. C. Vernooij, T. Huthwelker, H. Ade, D. Kilcoyne, T. Tyliszczak, R. H. Fink and C. Quitmann, Rev. Sci. Instrum., 2008, 79, 113704.

88 R. C. Moffet, T. Henn, A. Laskin and M. K. Gilles, Anal. Chem., 2010, 82, 7906-7914.

89 G. Cressey, C. M. B. Henderson and G. van der Laan, Phys. Chem. of Miner., 1993, 20, 111-119.

90 L. A. J. Garvie, A. J. Craven and R. Brydson, Am. Mineral., 1994, 79, 411-425.

91 R. A. Speers and M. A. Tung, J. Food Sci., 1986, 51, 96-98.

92 N. B. Wyatt and M. W. Liberatore, J. Appl. Polym. Sci., 2009, 114, 4076-4084.

93 A. K. Biń, Ozone-Sci. Eng., 2006, 28, 67-75.

94 F. H. Marshall, R. E. H. Miles, Y.-C. Song, P. B. Ohm, R. M. Power, J. P. Reid and C. S. Dutcher, Chem. Sci., 2016, 7, 1298-1308.

95 M. Shiraiwa, U. Pöschl and D. A. Knopf, Environ. Sci. Technol., 2012, 46, 6630-6636.

96 F. Jacobsen, J. Holcman and K. Sehested, Int. J. Chem. Kinet., 1998, 30, 215-221.

97 D. T. Sawyer, H. Sugimoto and T. S. Calderwood, Proc. Natl. Acad. Sci. U. S. A., 1984, 81, 8025-8027.

98 R. S. Smith and B. D. Kay, Nature, 1999, 398, 788-791.

99 A. Einstein, Ann. Phys., 1905, 17, 549-560.

100 W. Sutherland, Philos. Mag., 1905, 9, 781-785.

101 D. M. Lienhard, A. J. Huisman, U. K. Krieger, Y. Rudich, C. Marcolli, B. P. Luo, D. L. Bones, J. P. Reid, A. T. Lambe, M. R. Canagaratna, P. Davidovits, T. B. Onasch, D. R. Worsnop, S. S. Steimer, T. Koop and T. Peter, Atmos. Chem. Phys., 2015, 15, 13599-13613.

102 R. M. Power and J. P. Reid, Rep. Prog. Phys., 2014, 77, 074601.

103 J. Sujja-areevath, D. Munday, P. Cox and K. Khan, Eur. J. Pharm. Sci., 1998, 6, 207-217.

104 R. A. Gemeinhart and C. Guo, in Reflexive Polymers and Hydrogels: Understanding and Designing Fast Responsive PolymericSystems, ed. N. Yui, R. J. Mrsny and K. Park, CRC Press, Boca Raton, Fl, 2004, ch. 13: Fast Swelling Hydrogel Systems, pp. 245-257.

105 P. D. Oliveira, R. C. Michel, A. J. A. McBride, A. S. Moreira, R. F. T. Lomba and C. T. Vendruscolo, PLoS One, 2013, 8, 1-7.

106 D. Bergmann, G. Furth and C. Mayer, Int. J. Biol. Macromol., 2008, 43, 245-251.

107 M. Mobin and M. Rizvi, Carbohydr. Polym., 2016, 136, 384-393. 
108 R. Battino, T. R. Rettich and T. Tominaga, J. Phys. Chem. Ref. Data, 1983, 12, 163-178.

109 P. Corral Arroyo, T. Bartels-Rausch, P. A. Alpert, S. Dumas, S. Perrier, C. George and M. Ammann, Environ. Sci. Technol., 2018, 52, 7680-7688.

110 L.-K. Ju and C. S. Ho, Can. J. Chem. Eng., 1989, 67, 471-477.

111 F. J. Millero, S. Sotolongo and M. Izaguirre, Geochim. Cosmochim. Acta, 1987, 51, 793-801.

112 J. W. Moffett and R. G. Zika, Environ. Sci. Technol., 1987, 21, 804-810.

113 D. W. King, H. A. Lounsbury and F. J. Millero, Environ. Sci. Technol., 1995, 29, 818-824.

114 A. L. Rose and T. D. Waite, Environ. Sci. Technol., 2002, 36, 433-444.

115 R. Sander, Atmos. Chem. Phys., 2015, 15, 4399-4981.

116 Y. P. Lee, M. Fujii, K. Terao, T. Kikuchi and C. Yoshimura, Water Res., 2016, 103, 160-169.

117 D. R. Hanson and E. R. Lovejoy, Science, 1995, 267, 1326-1328.

118 D. R. Worsnop, J. W. Morris, Q. Shi, P. Davidovits and C. E. Kolb, Geophys. Res. Lett., 2002, 29, GL015542.

119 J. H. Kroll and J. H. Seinfeld, Atmos. Environ., 2008, 42, 3593-3624.

120 M. Hallquist, J. C. Wenger, U. Baltensperger, Y. Rudich, D. Simpson, M. Claeys, J. Dommen, N. M. Donahue,
C. George, A. H. Goldstein, J. F. Hamilton, H. Herrmann, T. Hoffmann, Y. Iinuma, M. Jang, M. E. Jenkin, J. L. Jimenez, A. Kiendler-Scharr, W. Maenhaut, G. McFiggans, T. F. Mentel, A. Monod, A. S. H. Prévôt, J. H. Seinfeld, J. D. Surratt, R. Szmigielski and J. Wildt, Atmos. Chem. Phys., 2009, 9, 5155-5236.

121 R. Volkamer, F. San Martini, L. T. Molina, D. Salcedo, J. L. Jimenez and M. J. Molina, Geophys. Res. Lett., 2007, 34, L19807.

122 X. Zhang, A. T. Lambe, M. A. Upshur, W. A. Brooks, A. Gray Bé, R. J. Thomson, F. M. Geiger, J. D. Surratt, Z. Zhang, A. Gold, S. Graf, M. J. Cubison, M. Groessl, J. T. Jayne, D. R. Worsnop and M. R. Canagaratna, Environ. Sci. Technol., 2017, 51, 5932-5940.

123 T. P. Riedel, Y.-H. Lin, Z. Zhang, K. Chu, J. A. Thornton, W. Vizuete, A. Gold and J. D. Surratt, Atmos. Chem. Phys., 2016, 16, 1245-1254.

124 V. F. McNeill, J. L. Woo, D. D. Kim, A. N. Schwier, N. J. Wannell, A. J. Sumner and J. M. Barakat, Environ. Sci. Technol., 2012, 46, 8075-8081.

125 Y. Zhang, Y. Chen, A. T. Lambe, N. E. Olson, Z. Lei, R. L. Craig, Z. Zhang, A. Gold, T. B. Onasch, J. T. Jayne, D. R. Worsnop, C. J. Gaston, J. A. Thornton, W. Vizuete, A. P. Ault and J. D. Surratt, Environ. Sci. Technol. Lett., 2018, $5,167-174$. 